\title{
LAS COMUNIDADES CAMPESINAS EN LA CULTURA CASTREÑA (1)
}

\author{
THE PEASANT COMMUNITIES \\ IN THE CASTREÑA CULTURE
}

\section{M. ${ }^{\mathrm{a}}$ DOLORES FERNÁNDEZ-POSSE $(*)$ F. JAVIER SÁNCHEZ-PALENCIA $(* *)$}

\begin{abstract}
The possibility that the social and economic structure of pre-roman castreñas (hillfort) communities corresponds to the concept of a peasant society is analysed. For this we make use of the archaeological record of the castros (hillforts) at the Archaeological Zone of Las Medulas, in the $S W$ of the province of Leon, at three levels of analysis: the units of occupation of the villages as basic cells of agricultural production and consumption; the suitability of the castros to be viewed as self-sufficient peasant communities; the specificity of their forms of life, rationality and economy as builders of a peasant landscape. In this way issues such as ownership and the degree and type of hierarchization of these communities are discussed.

The Roman presence in this area lead to a rapid process of dissolution of this native social structure. The mining interests promote a big change, both economic and social, which is visible in the population patterns and exploitation of the territory, in short, in the construction of a new mining landscape, besides the previous peasant one.
\end{abstract}

Palabras clave: Paisajes antiguos. Cultura Castreña. Sociedades campesinas. Zona Arqueológica de Las Médulas.

Key words: Ancient Landscapes. Castreña(hillfort) Culture. Peasant Societies. ArchaeologicalZone of Las Medulas. Educación y Cultura. El Greco, 4. 28040 Madrid.

(**) Departamento de Historia Antigua y Arqueología, C.E.H. CSIC. Duque de Medinaceli, 6. 28014 Madrid.

El artículo fue remitido en su versión final el 9-IX-98.

(1) Este trabajo se inserta en los Proyectos de investigación de la "Zona Arqueológica de Las Médulas" (ZAM), financiado por la Junta de Castilla y León, y "Paisajes antiguos en la Península Ibérica: Arqueología y Textos" (PAISAT) (PB94-0125), financiado por la DGICYT. Queremos agradecer particularmente la contribución de $\mathrm{B}$. Mariscal que ha realizado los análisis polínicos, y de los investigadores del Servei d'Analisis Arqueologiques de la UAB que, bajo la dirección de J. Estevez, han llevado a cabo la analítica zooarqueológica (M. Saña) y antracológica (R. Piqué).
En los últimos números de Trabajos de Prehistoria hemos tenido ocasión de leer algunos trabajos que aplican conceptos como campesinado o sociedades campesinas al estudio de las Edades del Bronce y del Hierro peninsulares (Díaz-del-Río, 1995; Parcero, 1995). Es, sin duda, una perspectiva interesante; e incluso se puede decir que doble- 
mente interesante porque los dos artículos citados se hacen desde la Arqueología del Paisaje. Nos ha atraído en particular aquél en el que César Parcero nos aproxima al carácter campesino de la Edad del Hierro en el Noroeste, es decir, de la Cultura Castreña, ámbito geográfico y cultural en el que creemos que el Proyecto Zona Arqueológica de Las Médulas puede aportar algo. Esa investigación, que realizamos en uno de los paisajes mineros más importantes y mejor conservados del Noroeste, reconocido como tal al haber sido incluido en 1997 en la Lista del Patrimonio de la Humanidad por la UNESCO, ha permitido conocer bastantes aspectos de esa sociedad castreña, indígena, anterior a la ruptura que supuso la presencia romana en su territorio y a las fuertes transformaciones económicas y sociales que generó la explotación del oro por parte de la administración romana. Hemos definido a esas comunidades indígenas en varias ocasiones, fuera en visiones generales (Sánchez-Palencia y Fernández-Posse, 1993; Sánchez-Palencia et alii, 1994, 1996), fuera profundizando en alguna cuestión más concreta (Fernández-Posse y SánchezPalencia, 1992; Fernández-Posse et alii, 1993; Fernández-Posse et alii, 1994) (Fig. 1).

En esos trabajos que no dejan de ser avances de los resultados de una investigación planteada a largo plazo, presentábamos a las poblaciones del segundo hierro del suroeste de León como pertenecientes a la Cultura Castreña del Noroeste, bien caracterizadas en sus poblados siempre bien visibles en el paisaje y perfectamente delimitados por un recinto construido. Ese recinto, una muralla perimetral y un foso que le sirve de cantera, es lo primero que levanta la comunidad que ha de habitarlo. Este primer trabajo colectivo se convierte en la referencia espacial para ordenar el poblado interior, cuyas construcciones se disponen en sucesivas bandas paralelas a la muralla respetando al pie de su paramento interno un espacio libre y de un carácter tan colectivo como ella misma. En el interior de ese recinto, que cumple una función social más allá del mero hecho defensivo, las viviendas están formadas por varias construcciones de funcionalidad diferenciada y con una estrecha relación espacial. Por el contrario, cada una de esas viviendas o unidades de ocupación se muestra sumamente independiente en el espacio construido: hacen un uso continuo de límites y marcas espaciales, la situación de sus entradas es excluyente en cuanto al espacio exterior a que abren y no se relacionan por medio de espacios libres o de tránsito, es decir, no
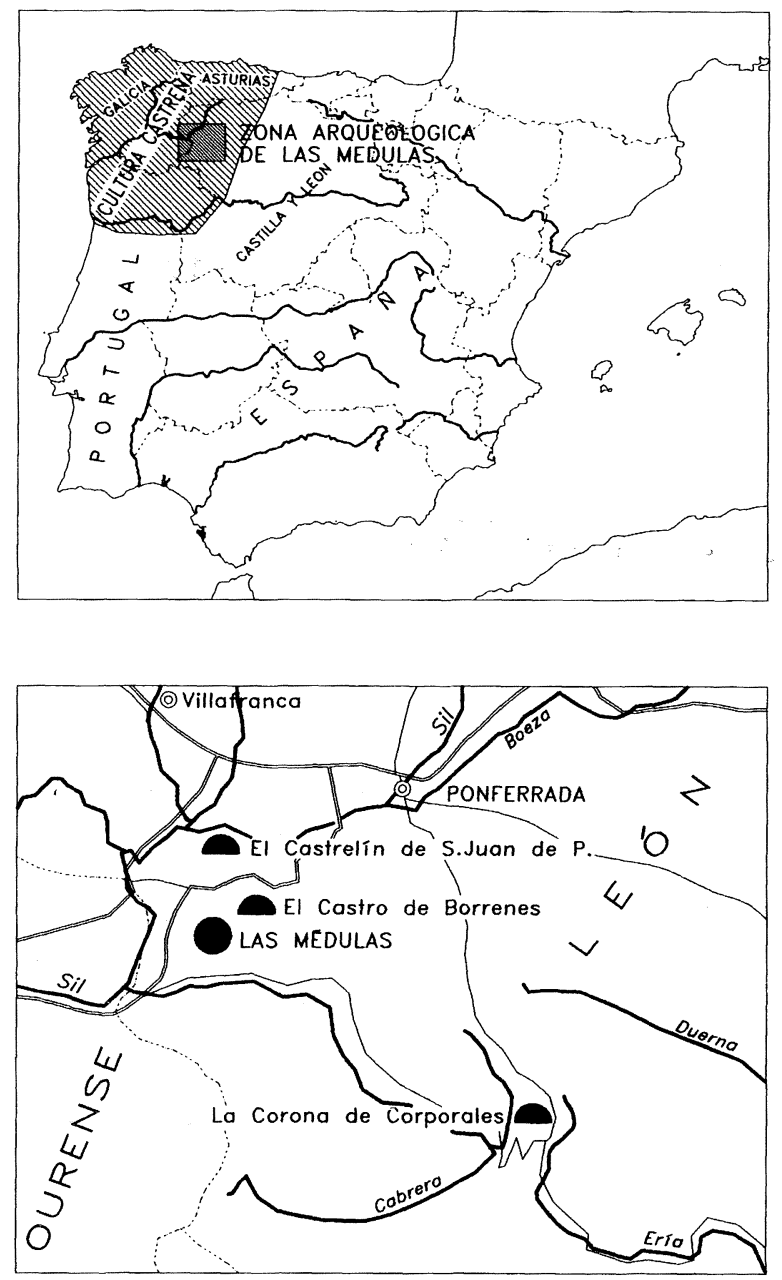

Fig. 1. Localización general de la Cultura Castreña y de la Zona Arqueológica de Las Médulas.

existen ni calles ni plazas. Cada vivienda, pues, evita toda relación espacial, y podría decirse que visual, con las restantes. De ello, así como de la superficie disponible por cada una de ellas, de su mobiliario y ajuar, se deduce la importancia del grupo familiar en la comunidad de cada castro; de igual forma que de esa vivienda tan privada y definida espacialmente puede deducirse una familia reducida y nuclear, de carácter muy cerrado.

Esa independencia espacial y social se corresponde además con una no menos marcada independencia económica, lo que convierte a cada vivienda en una unidad básica de ocupación y producción en cada castro. En efecto cada una de ellas presenta en su registro una clara tendencia económica, sea la producción agrícola representada en su almacén u hórreo, sean producciones más especializadas

T. P., 55, n. ${ }^{\circ} 2,1998$ 
como la metalúrgica o las manufacturas líticas (Fernández-Posse et alii, 1993). Pero lo más significativo desde el punto de vista que hoy queremos poner de manifiesto, es decir, la importancia del grupo familiar como unidad económica básica, es que cada unidad de ocupación tenga su propio almacén, a excepción precisamente de la dedicada al trabajo metalúrgico de las que hay una de ellas en cada castro.

Estos castros, es decir, esas aldeas de carácter cerrado y de economía casi autosuficiente rodeadas por una muralla que les proporciona una cohesión interna y permite su afirmación como comunidad frente a otras, son a su vez la unidad básica de estas poblaciones prerromanas en el territorio. Sus destacados emplazamientos buscan más la exhibición y el dominio del entorno inmediato que una ocupación global y conjunta de aquel. Generalmente aislados, median entre ellos distancias muy desiguales siendo, por contra, todos ellos de tamaño muy similar y, lo que es más importante, se trata de poblaciones concentradas sin pequeños asentamientos ni ningún otro tipo de ocupación entre ellas. Se sitúan en zonas potencialmente productivas, tanto para su subsistencia como para materias primas necesarias para la fabricación de su utillaje y herramientas. Es decir, en la elección de su emplazamiento prima, más que la presencia de un determinado tipo de recursos, una buena diversificación de todos ellos. Actúan, por lo tanto, con una marcada independencia en el espacio, sin que pueda hablarse de lugar central ni de jerarquización de asentamientos, algo que, además de en nuestra zona, parece poder decirse también de otras gallegas donde se han realizado estudios de corte territorial (Carballo, 1986, 1990, 1993; Rodríguez, 1986; Agrafoxo, 1989), aunque lamentablemente en la mayor parte de esos trabajos nunca se discriminan aquellos castros que son prerromanos de los romanos o de los que pertenecen a época romana, con lo que ello supone de distorsión en los modelos de ocupación y explotación del territorio resultantes. La razón de esa distorsión está, como es lógico, en que una vez la presencia romana es efectiva, la sociedad que trata de definirse en ellos -la prerromana indígena- ya no existe como tal o su estructura social ha cambiado de forma notable.

Así pues, al menos en estas zonas del occidente de lo que más tarde será la Asturia romana, el grado de interacción de las comunidades indígenas parece haber sido muy discreto una vez se sobrepasa la escala de la única unidad territorial reconoci- ble, es decir, el castro. Escasa integración a nivel regional que concuerda bien con la fraccionada estructura política que atribuyen las fuentes literarias a los pueblos del norte peninsular (Bermejo, 1986) y con los testimonios epigráficos que, aunque sean ya de época romana, pocas veces mencionan, para expresar el origen del individuo, una unidad organizativa más extensa que el castro, aunque no descartemos la existencia de un grupo mayor (González, 1986; Pereira, 1982, 1993). Por otra parte, ha de tenerse en cuenta que durante sus siglos de existencia estas comunidades de la Cultura Castreña debieron sin duda presentar procesos de regionalización (Carballo, 1993: 67) y desarrollos sociales diferenciados que la arqueología gallega no ha sido, todavía, capaz de señalar.

Esa lectura de cierto alcance social de los castros prerromanos del suroeste de León que hemos tratado de resumir en los párrafos anteriores tiene detrás un amplio registro arqueológico del que precisamente creemos que carecen otras propuestas. Sirva de ejemplo la falta de base empírica de que adolece el atractivo planteamiento de Parcero citado al inicio de este trabajo. Este autor (Parcero, 1995: 131) presenta un modelo hipotético que, como tal, es racional y plausible, pero su validación, lo que el mismo denomina contrastación a través de la documentación arqueológica (1995: 131), sigue siendo un modelo teórico. Para poder hablar de ese carácter campesino de la sociedad castreña es necesario, en nuestra opinión, pasar o descender del territorio, del paisaje, al yacimiento y a sus reales y básicas unidades económicas; al igual que se hace necesario ir más allá de esos datos generales -por otra parte necesarios y a veces ordenadamente presentados (Vázquez, 1983, 1986; Aira et alii, 1989; Ramil, 1994; Aira, 1996)- que dejan en una afirmación obvia la economía agropecuaria de esas comunidades, como es fácil comprobar en las últimas, y por cierto numerosas, síntesis sobre la cultura castreña.

En nuestra opinión es necesario, por tanto, descender a esa más adecuada escala de análisis de la estructura interna de los castros para poder siquiera plantear si la sociedad castreña fue, en algún momento de su desarrollo y en alguna zona, una sociedad campesina. Y esto porque en la mayor parte de los estudios campesinos, cualquiera que sea su tradición conceptual, la unidad básica es la familia o, dicho de otra forma, en todas ellas se reconoce la relevancia de la economía familiar en las sociedades campesinas (Shanin, 1979: 25 y 1983: 
276; o el propio Parcero, 1995: 130). El valor de la familia campesina como una herramienta conceptual válida en ese tipo de estudios fue puesta de manifiesto por Chayanov, ya en 1925, en su Teoría de la Economía Campesina. Por otro lado, esa tradición de estudios campesinos iniciada por ese economista ruso mantiene que lo que determina la estructura social del campesinado es un tipo específico de economía (Kerblay, 1979: 133). Ese nos parece el enfoque más adecuado para estudiar, desde la arqueología, sociedades desaparecidas y que no alcanzaron el nivel de complejidad necesario para llegar a ser estatales. En el sentido de que quizás desde esa posición, y no desde otra, sea posible analizar hasta que punto la sociedad castreña fue una sociedad campesina, no en vano el registro económico es más explícito que otros para el arqueólogo.

No vamos, puesto que es algo claramente fuera de nuestro alcance, a definir qué es una sociedad campesina de la Edad del Hierro ni a verificar si existe en ella un modelo sociológico o antropológico (que serían otros dos posibles enfoques del análisis) que pudiera denominarse campesino, pero tenemos el convencimiento de que cada sociedad antigua tuvo su propio proceso, nunca simple y claro, y que pueden ser campesinas tipos cualitativamente muy diferentes de organización social (Shanin, 1979: 14). En todo caso el valor del concepto sociedad campesina aplicado a la sociedad castreña reside en su capacidad para explicar algunos datos empíricos de su registro arqueológico.

Vamos a ver, en primer lugar, hasta que punto la sociedad castreña que define la arqueología se acomoda a la definiciones usuales de esas sociedades campesinas. Para ello pasaremos revista a la unidad doméstica, no en vano la primera condición de la economía campesina es la integración de la vida familiar y la actividad agrícola. En un segundo apartado trataremos el nivel superior, dentro del mismo discurso, es decir, la aptitud de los castros para ser considerados comunidades aldeanas, y, por último, pasaremos al espacio entendido como territorio, tanto en su vertiente económica como social.

\section{LAS FAMILIAS CAMPESINAS DE LAS UNIDADES DE OCUPACIÓN DE LOS CASTROS PRERROMANOS}

Las excavaciones en castros prerromanos llevadas a cabo dentro del Proyecto ZAM han puesto al descubierto suficiente extensión de sus núcleos edificados (concretamente 40 construcciones y 15 espacios complementarios entre La Corona de Corporales y El Castrelín de San Juan de Paluezas) para entender su estructura interna. En efecto, una vez sometidas todas esas construcciones a un triple análisis, constructivo, funcional y espacial, puede determinarse que, pese a su aparente homogeneidad, hay entre ellas notables diferencias de factura con una escala bien graduada en la inversión de recursos, trabajo y tiempo que se corresponde, además, con su funcionalidad. Unido esto a sus nítidas y formalizadas relaciones espaciales pudimos definir qué era una unidad de ocupación, término equivalente a vivienda con una lectura social defamilia. Preferimos, sin embargo, el empleo de la expresión unidad de ocupación porque tiene capacidad para dar cabida a otras características o atributos, como el hecho de que se supere el mero contenido doméstico. En efecto, esa unidad es el elemento articulador de la ordenación y desarrollo del espacio construido, el núcleo económico básico como organizador de la producción y el mecanismo de regulación y control del comportamiento y relaciones sociales de la comunidad que es el castro.

Así pues, las unidades de ocupación de los castros transcienden lo puramente doméstico. Su doble cualidad de unidad social y productiva y el hecho de que la casi totalidad de las puestas al descubierto tengan como tendencia económica las actividades agropecuarias, las acercan a las definiciones de la familia campesina que se formulan en los estudios sectoriales. Es decir, aquella que se caracteriza por ser simultáneamente productora y consumidora de su propio trabajo. O dicho de forma más clara, aquella en que el objetivo de su trabajo es el propio consumo y su mano de obra es, de forma exclusiva, todos los miembros, sin distinción de edad ni sexo, de esa familia que se convierte de este modo en el núcleo básico de la sociedad campesina (Shanin, 1979: 25-26; 1983: 276-277), cualquiera que sea su época (Rösener, 1990: 183-187) ya que, como forma social que es, se diferencia estructuralmente de otros tipos de familia. Vamos a verlo con más detalle:

\section{a) Los almacenes como indicadores de la actividad agropecuaria}

En los dos castros citados hemos definido en toda su superficie 12 unidades de ocupación (Fig.

T. P., 55, n. ${ }^{\circ} 2,1998$ 
La Corona de Corporales
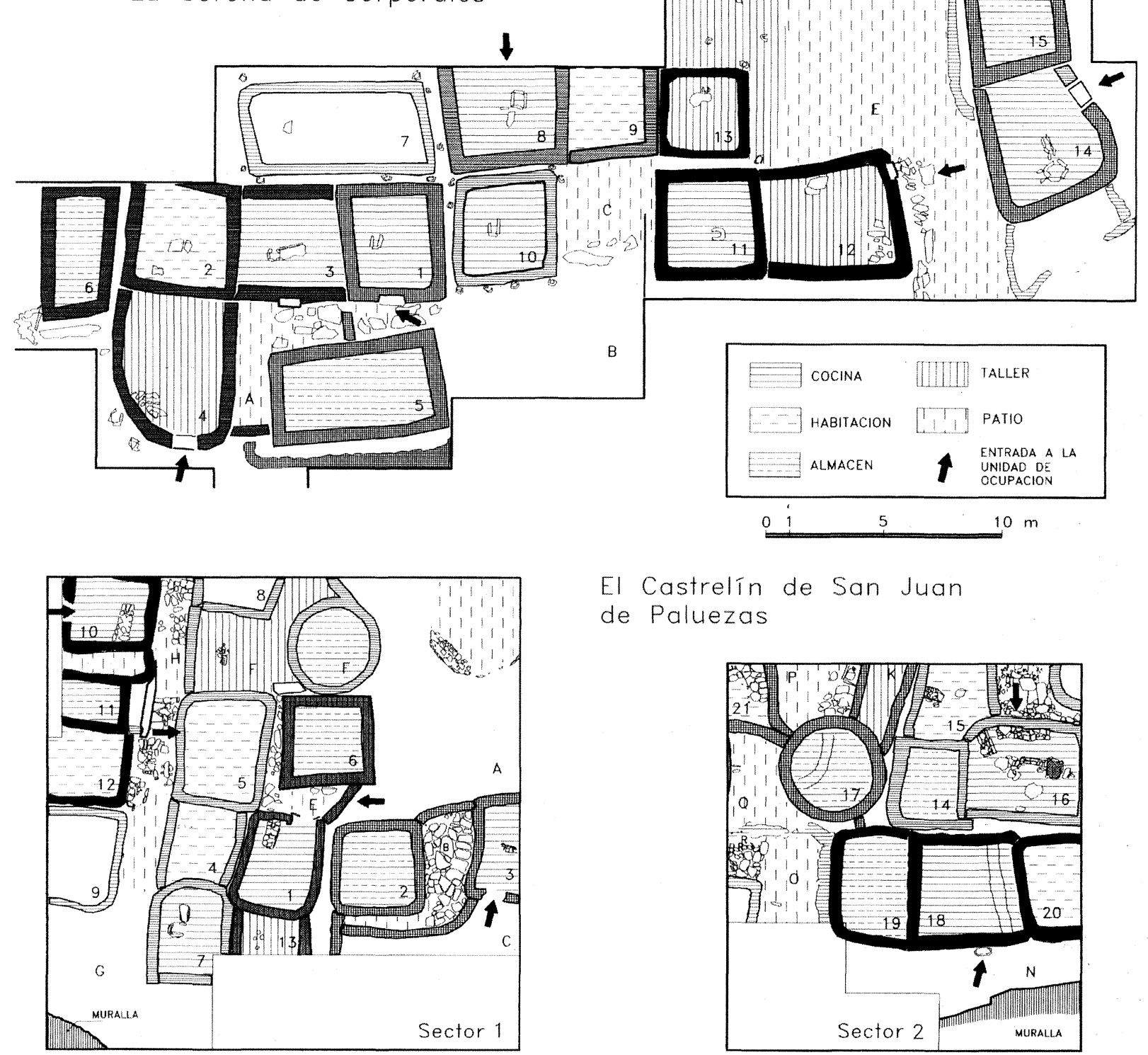

El Castrelín de San Juan

de Paluezas

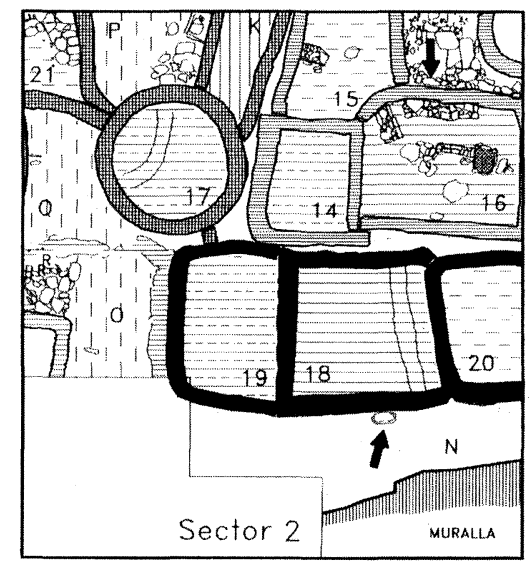

Fig. 2: Unidades de ocupación con la funcionalidad de sus construcciones en algunos de los sectores excavados en los castros prerromanos de La Corona de Corporales y El Castrelín de San Juan de Paluezas (las unidades de ocupación van diferenciadas por la trama de relleno de sus muros).

2) de las que, al menos 9, tienen como principal tendencia económica la agricultura. Tal afirmación se basa en la presencia entre sus construcciones de una dependencia especial que, como ya apuntamos, funciona como habitación de almacenaje u hórreo.

Estos almacenes son el tipo de espacio mejor definido constructivamente y su superior factura los discrimina fácilmente del resto, sean éstos cocinas, talleres, corrales o anejos de habitación. Los sepa- ra la elección y el grado de manipulación a que han sido sometidos los materiales utilizados en su cons= trucción, como son, por ejemplo, el mayor tamaño y mejor corte de las piedras utilizadas en sus muros o la abundancia y el cuidado tratamiento previo de la arcilla que se usa como trabazón. Asimismo son mucho más cuidadas sus características constructivas en relación con las habitaciones de otra funcionalidad. Los almacenes están, en efecto, levantados 

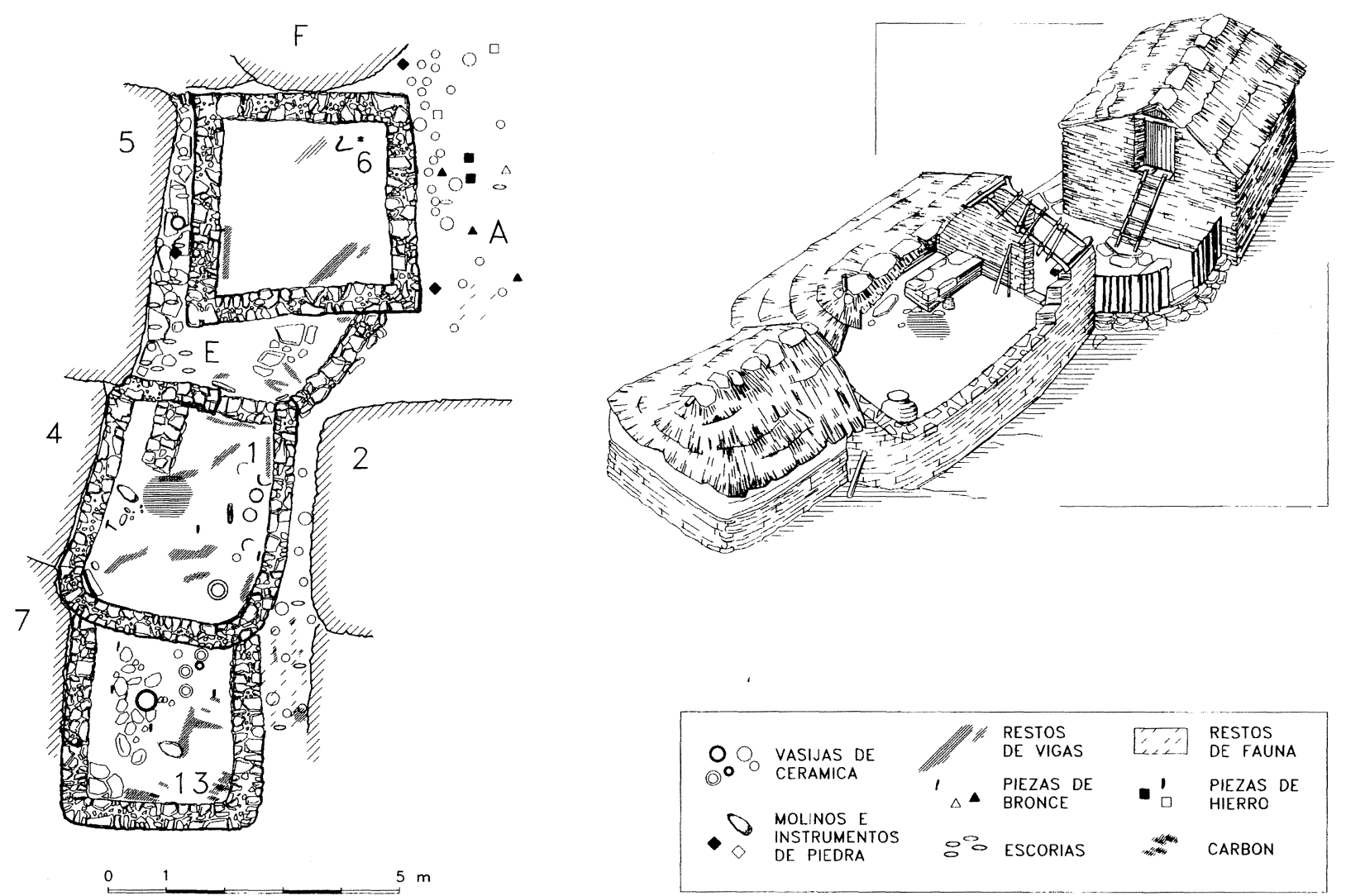

Fig. 3. Reconstrucción ideal de una de las unidades de ocupación de El Castrelín de San Juan de Paluezas.

con muros más anchos y de trazado más regular, están dotados de cimientos, y sus plantas, aunque de formas diversas como se ve en la figura citada, son siempre las mejor definidas desde el punto de vista formal, con sus esquinas resueltas de la misma manera. Son además el único caso en que se da la planta circular. Por otra parte, poseen los mejores pavimentos situados a una cota superior a los del resto de las construcciones y a los espacios exteriores, para lo cual se utilizan potentes capas niveladoras previas y su puerta se sitúa a una altura bastante superior al nivel del suelo (Fig. 3). Están dotados de dispositivos exteriores, como aceras, bancales, enlosados, conducciones, etc. En definitiva, todas sus características constructivas se encaminan a lograr un óptimo aislamiento del exterior, sobre todo de los animales y de la humedad. El objetivo parece pues tratar de evitar los posibles deterioros de su contenido, característica común a los lugares de almacenamiento de alimentos, forraje y, en general, de materias perecederas.

Por otra parte, ese aislamiento logrado por métodos estrictamente constructivos se refuerza por cuidadosos mecanismos espaciales. Son construcciones que generalmente se levantan aisladas y se mantienen así; en los pocos casos en que aparecen adosados a otra construcción se utiliza algún tipo de estratagema que mantenga ese buscado aislamiento, a veces difícil de conseguir en la densa trama de la edificación. Sirve de ejemplo el caso del almacén 15 contiguo a la cocina 14 en La Corona de Corporales que lo consigue por medio de una clara diferencia de cota en su pavimento (Lám. I).

La funcionalidad que atribuimos a estas características construcciones concuerda con su falta de mobiliario y ajuar doméstico. De hecho los almacenes carecen absolutamente de hallazgos, a excepción de algún elemento de hierro, como clavos, alcayatas o ganchos, o restos de vegetales carbonizados. Esta total ausencia de materiales, a la que se une una excepcional limpieza en lo que se refiere a restos de fauna, puede llegar a generar alguna duda sobre su funcionalidad. Su excelente factura y pulcritud podría relacionarse con una función más elevada, sin embargo, cualquier sugerencia en esa línea debe ser descartada. Basta tener en cuenta 


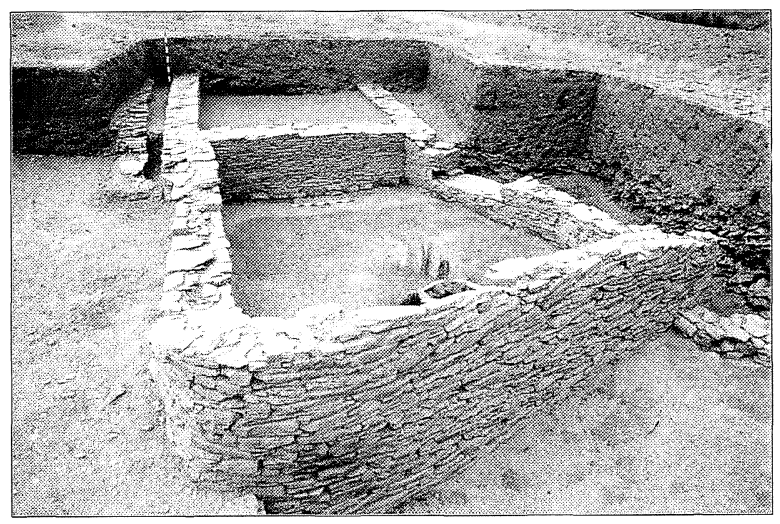

Lám. I. La Corona de Corporales. Cocina y almacén de una de las unidades de ocupación.

algunos de sus tamaños mínimos, como el 6 en La Corona o el 11 en Castrelín (Fig. 2). Por otro lado y como argumento contrario debe tenerse en cuenta la falta de otro tipo de contenedores en el poblado. No hay silos excavados en el suelo -como los que aparecen en otros círculos culturales de la misma época- ni grandes vasijas que parezcan haber servido para el almacenamiento de alimentos. Las características grandes orzas de boca cerrada y panza desarrollada que suelen aparecer, casi siempre junto a los molinos y molederas, en las proximidades de los hogares de las construcciones utilizadas como cocinas atestiguan por sus concreciones internas que fueron contenedores de agua.

La ausencia de esas vasijas de almacenamiento -tanto en los propios almacenes como en el resto de las construcciones- puede deberse a la utilización de otro tipo de materia como la madera, la cestería o el tejido, que podría cumplir tales funciones en un ambiente tan bien acondicionado como el de esas construcciones específicas y cuya huella en el registro arqueológico es mucho menos evidente. Pueden objetarse también otras ausencias como son la de los testimonios directos de grano u otros tipos de restos carpológicos, algo que lamentablemente no hemos podido documentar. En este sentido son interesantes las evidencias proporcionadas por la analítica polínica y antracológica realizada hasta el momento.

Si finalmente se aceptan estas peculiares construcciones como significantes de esa agricultura de subsistencia, aún hay otra circunstancia que es interesante señalar. En el registro constructivo es la dependencia que muestra más oscilación en sus superficies útiles. Ya hemos visto que no todas las viviendas poseen almacenes de igual capacidad.
Sus superficies oscilan entre los algo más de $4 \mathrm{~m}^{2}$ del 11 de El Castrelín y los casi $18 \mathrm{~m}^{2}$ del 5 de $\mathrm{La}$ Corona. Y aunque este espacio está en algunos casos considerablemente ampliado por la presencia de un sollado o altillo, como en el caso del citado almacén 5 en La Corona, nunca sobrepasa demasiado el $50 \%$ de la superficie útil de la unidad de ocupación. En esta misma línea queda de manifiesto la indudable relación proporcional que existe entre el tamaño del almacén y las actividades o tendencias económicas que presentan algunas de las unidades de ocupación. Así, en la misma Corona de Corporales, ese pequeño almacén 6 de $9 \mathrm{~m}^{2}$ pertenece a una unidad de ocupación que cuenta entre sus construcciones con una dedicada a la fabricación de útiles líticos, actividad, esta última, que parece por ello haber sido realizada a tiempo parcial. De igual forma, y de manera más categórica, la que se dedica a la producción metalúrgica carece por completo de almacén, atestiguando su dedicación completa a esa actividad (Fig. 2).

Como conclusión puede señalarse la clara importancia de estas dependencias de almacenaje en el registro constructivo del poblado. Es la habitación de la vivienda en la que se ha invertido más recursos, discriminándose del resto por su calidad. Permite, además, atribuir a la mayoría de las viviendas, y por tanto a las familias, una actividad agrícola y recolectora propia, y al parecer autárquica, dentro de cada unidad de ocupación. Sólo quedarían exceptuadas aquellas que, careciendo de esta dependencia o reduciendo su tamaño, realizan otro tipo de actividad productiva.

\section{b) Caracterización de la familia campesina: los almacenes en la unidad de ocupación}

Si tomamos como referencia los datos inferidos de número de miembros de la familia que queda indicado en las superficies útiles de las unidades de ocupación en los sectores excavados y tenemos en cuenta que en los recintos de estos castros sólo se ocupa una banda paralela a la muralla quedando su centro sin edificar, podemos calcular que el número de unidades de ocupación en La Corona fueron, como mucho, en torno a las 35 (Fernández-Posse y Sánchez-Palencia, 1988: 227) y en El Castrelín entre 25 y 30 (Lám. II). Se trata de poblados, por tanto, con un número de habitantes que estaría entre 120 y 160 . Una gran parte de ellos se dedicaban a las actividades agropecuarias. Quedaban exentos 


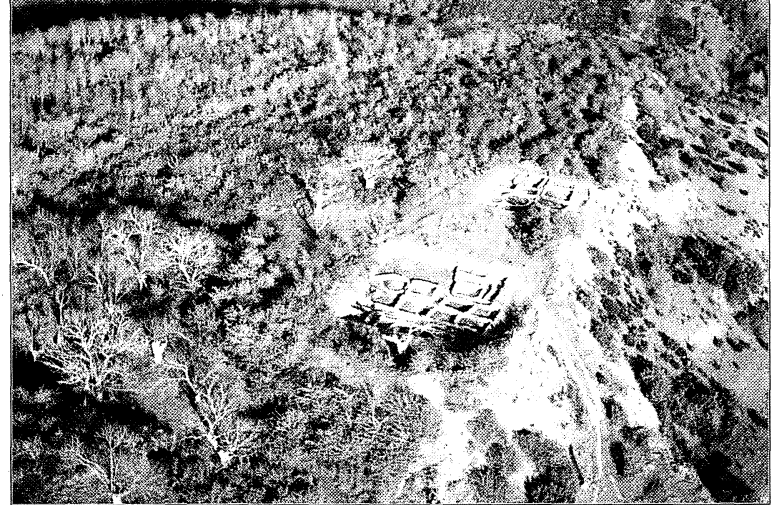

Lám. II. Fotografía aérea oblicua de los sectores excavados en El Castrelín de San Juan de Paluezas.

o veían reducidas su participación en ese tipo de actividad las producciones especializadas documentadas -como la metalurgia del bronce y hierro y la fabricación de útiles líticos-y otras que hemos de suponer, como las manufacturas cerámicas. Todas esas actividades se llevaban a cabo en la unidad familiar, por lo tanto puede decirse que el $80 \%$ de las unidades de ocupación tenían como actividad prioritaria la producción de bienes de subsistencia. Puede concluirse, pues, que en cifra indicativa el mismo porcentaje de la comunidad de cada castro era agricultora, proporción que supera con creces a las exigencias que la mayor parte de los autores proponen para considerar a una comunidad como campesina. Con las reservas de que tales exigencias se refieren a contextos históricos y sociales modernos (Thorner, 1979: 182) que utilizamos por carecer de referencias respecto a sociedades antiguas como la castreña.
Otra exigencia, ya mencionada, para considerar campesina a una comunidad es la integración de la vida familiar y la actividad agrícola que se presenta, además, como la condición primera de ese tipo de economía. Tal condición queda particularmente clara en las unidades de ocupación de nuestros castros. En primer lugar se ve en el desarrollo del espacio edificado. Así al levantar una de esas unidades, y según la secuencia constructiva, las primeras dependencias son siempre las dos habitaciones que representan en el registro funcional esas dos actividades básicas de la familia campesina: cocina y almacén. Casi siempre construidas exentas, son puestas de inmediato en relación espacial por medio de otras dependencias auxiliares o menores, sean patios, corrales o vestíbulos, como es el caso de la unidad de ocupación de la vivienda 1 del Castrelín (Fig. 3). Hay lógicamente necesidades, también más o menos inmediatas, que obligan a ampliar esos primeros espacios con otras dependencias anejas con funcionalidad de habitación o taller, de forma que las unidades de ocupación pueden llegar a tener en algún caso un buen número de habitaciones. También son frecuentes, por iguales necesidades de espacio, fuertes reformas constructivas con cambio de funcionalidad y reconstrucción de algunas construcciones deterioradas. De todos esos cambios resulta expresiva la evolución constructiva de la unidad de la vivienda 7 del castro citado (Fig. 4), doblemente interesante para el tema de este trabajo ya que en el último momento desaparece el almacén $\mathrm{F}$ cuando la unidad de ocupación se orienta a otras producciones. Pero en ese contexto relativamente dinámico nunca se construye un segundo almacén ni el que ha sido construido en primer lugar se am-
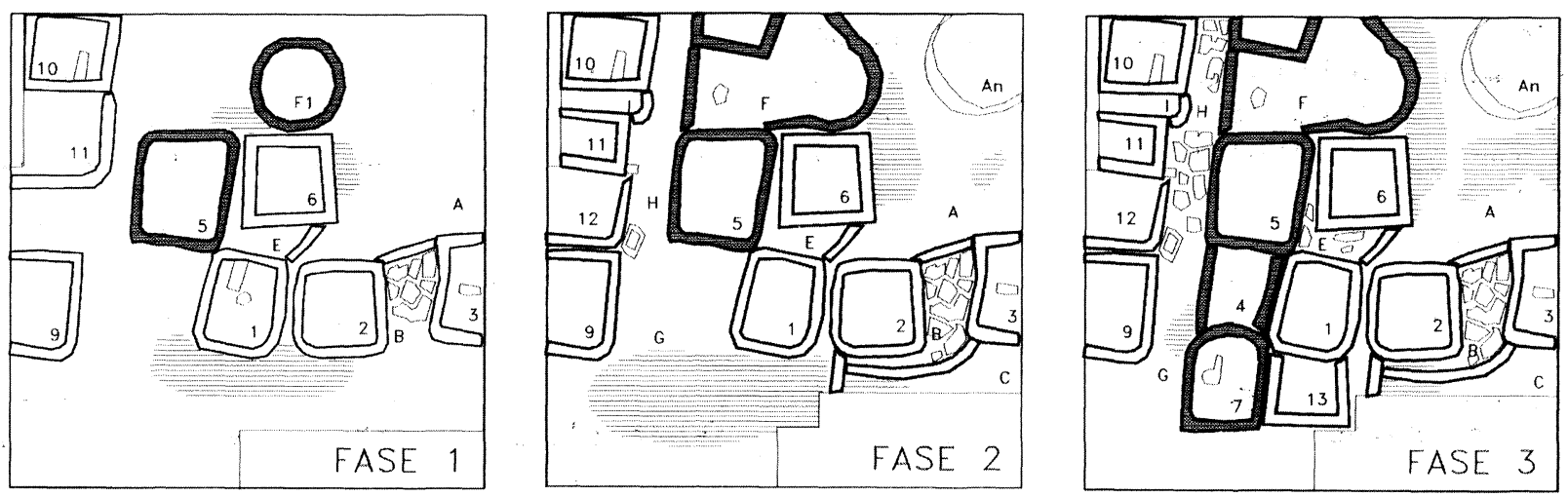

Fig. 4. Secuencia constructiva de una de las unidades de ocupación del sector 1 del Castrelín de San Juan de Paluezas. Puede observarse los cambios en los espacios de vertido de desechos y en la funcionalidad de las construcciones. 
plía. Podría pues plantearse que existe un tope de almacenaje y por tanto de la producción, supeditándose el tamaño de los almacenes a lo estrictamente necesario para cubrir las necesidades subsistenciales de la familia sin que tenga demasiada cabida el excedente.

Puede decirse, por lo tanto, que los almacenes aseguran la subsistencia de la unidad de ocupación caracterizándose como un espacio privado que define a la familia que la ocupa como grupo productivo. Asimismo, señalan no sólo esa integración de la producción subsistencial en el grupo familiar sino que marcan los límites de la misma producción.

Si se supera el análisis del almacén como dependencia y se analiza ahora en el conjunto del espacio doméstico del poblado, quedan de relieve otros rasgos que han sido señalados como propios o definidores de las sociedades campesinas. En primer lugar la marcada independencia espacial de las unidades de ocupación con la consiguiente independencia de la familia que la habita -núcleo cerrado y cohesivo con escasa relación con el exterior-y el autarquismo que de ella se deriva. En este sentido concuerda con la mayoría de los autores de estudios campesinos que suelen establecer como unidad básica de esas sociedades a granjas aisladas que actúan como unidad familiar y unidades básicas de producción. Sobre todo porque deben ser entidades definidas, estando algún autor tentado de llamarlas independientes (Shanin, 1979: 185). Esta característica se corresponde bien con la falta de contacto espacial y aún visual de nuestras unidades de ocupación dentro del espacio doméstico de los castros. Quedan muy bien definidas por esos caleyos, muros dobles y otras marcas espaciales, que las aíslan dentro del propio poblado. De hecho las insularizan (Fig. 5) de tal forma que no se integran en un espacio articulado y, como dijimos, no se relacionan espacialmente por medio de calles ni plazas. Actúan, en definitiva, como esas granjas aisladas.

Otra serie de cuestiones también ponen de manifiesto esa voluntad de aislamiento y autosuficiencia de las unidades de ocupación. Los ajuares, por ejemplo, señalan que cada grupo familiar atiende a sus necesidades en la mayor parte de bienes de consumo, de forma que útiles de tejer o de tratamiento de pieles aparecen en cada unidad. Pero, sobre todo, es significativa la presencia de los que se utilizan en la molienda: cada familia almacena y transforma sus productos agropecuarios. Nada más lejos de esas zonas comunes o colectivas de transformación de productos de primera necesidad propias de otros círculos culturales.

Esta primera lectura económica y social del espacio doméstico de los castros leoneses parece corresponderse con el diseño que la mayor parte de los autores hacen de las sociedades campesinas. Estamos ante una sociedad formada por familias cerradas y autosuficientes donde el individuo pierde protagonismo y parece haber tenido que pertenecer, en cualquier momento de su vida, a una de esas unidades de ocupación. Puede establecerse la existencia de un parentesco excluyente de la misma manera que tales unidades poseen un entrada, un almacén y una producción igualmente excluyentes respecto a las demás. Cada familia cuenta con su propia fuerza de trabajo para generar sus propios recursos.

Con razón podemos decir que en estas comunidades castreñas no es el individuo sino la familia la base de las relaciones sociales; familia de la que puede decirse, a su vez, que está muy individualiza$d a$. Cuestión de suma importancia a la hora de definir aspectos de una estructura social que, en una primera lectura de su registro arqueológico, no deja de manifiesto una jerarquización clara y permite analizar determinados aspectos-por ejemplo, bienes de prestigio tan evidentes como la orfebrería- como elementos de carácter no estrictamente individual.

En ese sentido es también interesante señalar que, al igual que en otras sociedades campesinas, a ese bajo nivel de relación entre las unidades de ocupación, generado por la escasa necesidad -exceptuando producciones especializadas como la metalúrgica o la lítica-que experimentan unas de otras, se une el que todas parecen vivir en unas similares condiciones, es decir, su aparente igualdad. Autores como Shanin o Stirling (1979), aunque siempre refiriéndose a contextos campesinos modernos, expresan a este respecto que no hay muchas diferencias de riqueza en una aldea campesina. En efecto, todas las unidades de ocupación muestran una aparente igualdad en lo que se refiere a su mobiliario y ajuar. No sucede lo mismo en el espacio útil disponible en cada una de ellas con diferencias a veces bastante contrastadas. Tanto en La Corona como en El Castrelín (Lám. III) hay ejemplos expresivos de esas diferencias que oscilan entre las unidades que no alcanzan los $30 \mathrm{~m}^{2}$ y las que superan los 70 , por más que la mayoría se sitúe en torno a los $50 \mathrm{~m}^{2}$. Si es cierto que esta disponibilidad de espacio se puede interpretar como indicador de distancia social entre las familias de las respectivas unidades de ocupación, las diferencias quedan muy paliadas cuando 




Fig. 5. Diagramas de circulación y privacidad en el sector 1 de El Castrelín de San Juan de Paluezas. 


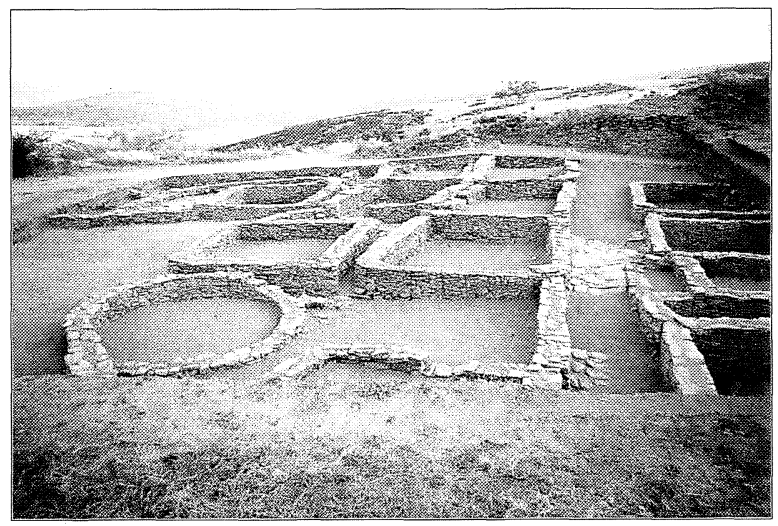

Lám. III. Vista general del del sector 1 de El Castrelín de San Juan de Paluezas.

se analizan desde el punto de vista funcional. La amplia superficie de algunas parece quedar justificada en la mayor necesidad de espacio que experimentan aquellas que se dedican a alguna actividad especializada, como la metalurgia. De hecho el contraste de espacio disponible es mucho menor en las que se caracterizan por la presencia exclusiva de un almacén. Por lo tanto, si el factor nivel de vida se reduce a la comparación de las superficies estrictamente domésticas estaremos ante distancias sociales mínimas. Algo que se refleja quizás mejor si se expresa el espacio disponible por porcentajes de dedicación: tanto la funcionalidad doméstica como la que podríamos denominar económica (almacenes, talleres o ambos tipos de espacio) se cifran en torno al $40 \%$ de la superficie total en todas las unidades de ocupación.

Podemos pues afirmar que las diferencias aparentemente acusadas entre las unidades de ocupación, tanto en número de construcciones y espacios auxiliares como en metros útiles disponibles, quedan bastante matizadas cuando tales superficies se expresan en porcentajes funcionales. Algo que unido a las escasamente significativas diferencias en equipamiento y confortabilidad y ajuar parece situarnos ante una sociedad donde cada unidad accede de forma relativamente igualitaria a los bienes de consumo cotidiano. Esto no debe hacer pensar que estamos ante una sociedad de las llamadas igualitarias, pero esa discreta variación en el registro de las unidades de ocupación concuerda muy bien con la forma de manifestarse la jerarquización en las sociedades campesinas que no se basa, precisamente, en un acceso diferencial a la riqueza material, por más que tengan en ellas cabida otro tipo de autori$d a d$, como luego veremos.
Concluiremos, por el momento, que la unidad de ocupación de los castros parece obedecer a la existencia de una familia campesina que es, a su vez, la unidad básica de producción y consumo salvo en aquellas producciones que necesitan un cierto nivel de especialización y la utilización de materias primas poco habituales.

Esto último requiere quizás algunos comentarios sobre el componente tradicional admitido como propio de las sociedades campesinas. Se trata quizás de un terreno más ambiguo -o de carácter más sociológico- pero que no está ausente del registro arqueológico. Nos referimos a algunos rasgos considerados clásicos dentro de lo que puede denominarse racionalidad campesina. Una característica señalada en las sociedades estables formadas por unidades o segmentos cerrados es, por ejemplo, no querer maximizar su producción. En La Corona hay poca secuencia para evaluar cambios que puedan indicar una intensificación de la producción, ya que fue ocupada solamente por dos o tres generaciones antes de su destrucción, pero en El Castrelín su secuencia de más de dos siglos permite comprobar los escasos cambios en la producción agropecuaria. Es decir, mientras crece la población, se levantan cada vez más unidades de ocupación, hay frecuentes reformas constructivas, se funde gran cantidad de hierro, etc., la cabaña ganadera que se documenta a través de los restos de fauna recogida en los basureros más antiguos en nada se diferencia de la de los más modernos y no hay ningún caso en que se amplíen los almacenes, aunque es relativamente corriente que eso suceda en otro tipo de dependencias.

Esto puede achacarse a otra de las características de las familias campesinas: la carencia de un concepto de rentabilidad y ese no distinguir demasiado un excedente en la producción. Es decir, no se trata de obtener ganancia. La economía dentro de esa unidad básica y familiar se produce en régimen de autoexplotación hasta cubrir sus necesidades de subsistencia y lograr un equilibrio entre trabajo y consumo. Junto a ese aspecto otro también considerado propio de la racionalidad campesina: no correr riesgos o minimizarlos dentro de un universal del campesino, por naturaleza socialmente conservador, como bien explica Díaz-del-Río (1995: 107). En ese espíritu se entienden bien algunas características del utillaje utilizado por estas comunidades castreñas, como es el caso de que sigan usando molinos de tipo barquiforme o planos incluso en asentamientos de época romana; o que su metalur- 
gia no alcance en parte de su producción un nivel tecnológico que de forma indudable posee el artesano metalúrgico (Fernández-Posse et alii, 1993: 212-214). Lo que los investigadores suelen considerar anacronismos culturales parecen tratarse mas bien de un conservadurismo basado en la falta de sentido que en su modo de producción tiene conceptos como rentabilidad o competitividad.

Habrá que volver sobre alguna de estas cuestiones propias de la racionalidad campesina a lo largo del trabajo, pero antes parece conveniente pasar al nivel suprafamiliar, es decir, al funcionamiento del castro como grupo, como comunidad, y analizar hasta qué punto, a ese nivel, se puede seguir hablando de una sociedad campesina.

\section{EL CASTRO: UNA COMUNIDAD ALDEANA AUTOSUFICIENTE}

Si la unidad de ocupación es el núcleo básico desde el punto de vista social y económico dentro de cada una de las comunidades prerromanas, el castro es el grupo esencial cuando se habla de poblamiento castreño, en el sentido de que la arqueología no ha documentado, por el momento, ni núcleos de población menores ni cualquier otro tipo de organización territorial o económica superior de la que formen parte. Añadamos a esto el considerable grado de autonomía o independencia con que actúan en el territorio, esto es, unos castros con respecto a otros, como ya dijimos.

Los castros son desde ese punto de vista agrupaciones de unidades de ocupación -o de familias nucleares-rodeados de visibles murallas y fosos, separados entre sí por lo que parece ser una tierra de nadie. Así lo indica el modelo de ocupación del territorio que hemos expuesto someramente en la introducción y más detenidamente en algunas de nuestras publicaciones ya citadas. Las distancias que los separan son tan arbitrarias que tan pronto quedan separados por la media hora escasa que hay entre el Castro de Borrenes y El Castrelín como por la jornada larga que habría que emplear para ir de ellos a La Corona de Corporales. Aunque no sea el momento de entrar en detalles, recordaremos a este respecto que en la mayor parte de los estudios de corte espacial en el ámbito cultural del Noroeste (Carballo, 1993) casi todos los intentos de establecer diferenciación funcional y jerarquización de asentamientos o modelos de lugar central han resultado fallidos.

\section{a) La estructura interna del poblado}

De lo que hemos expuesto hasta el momento, se desprenden las fuertes relaciones de complementariedad económica que existen entre las unidades de ocupación por encima de su fuerte independencia espacial y tendencia autosuficiente. Aquellas que se dedican a producciones especializadas dependen de las dedicadas a la actividad agropecuaria para todos o parte de los bienes de subsistencia, pudiendo deducirse la existencia de un intercambio que se produce en el ámbito del poblado. Pero además de que esos grupos familiares sean claramente complementarios dentro de ese poblado, existe otra circunstancia que nos presenta a las comunidades de los castros como grupos económicos solidarios: sólo uno de ellos se dedica a esas producciones especializadas y estas existen en todos los poblados. De esta forma la estructura productiva nos lleva a una sociedad cohesiva y bien articulada una vez que se supera la escala de ese cerrado grupo familiar que definen las unidades de ocupación. Cada castro se abastecía, pues, no sólo de los recursos agropecuarios de subsistencia sino de manufacturas tan imprescindibles para la obtención de esos bienes de consumo como era el propio utillaje agrícola o de los elementos de transformación de alimentos como son los molinos.

En el registro constructivo encontramos además otros indicadores de esa cohesión social que contrarrestan las tendencias sociales centrífugas o disgregadoras propias de esos grupos cerrados e independientes -desde el punto de vista espacial, visual y económico-que son las unidades de ocupación. El más significativo es la clara delimitación del recinto que convierte a los castros, con su murallas y fosos, en espacios cerrados perimetralmente. Es decir, esas obras de delimitación, generalmente muy visibles, trascienden su primario significado defensivo para cumplir una función social. Esto queda de manifiesto en varias circunstancias ya apuntadas, que van desde ser la primera obra que realiza el grupo, una vez tomada la decisión de fundar un poblado, hasta que el trazado de la muralla sea el referente para la ordenación del espacio construido en su interior o, también, que se reserve siempre un espacio libre sin que se produzcan los adosamientos de construcciones acostumbrados en otros grupos culturales.

La importancia y significación social de la muralla y el carácter cerrado y cohesivo de que dota a la comunidad o grupo castreño conviene muy bien

T. P., 55, n. ${ }^{\circ} 2,1998$ 
a su economía autárquica y parece responder a la necesidad de algunas sociedades agrícolas o agriculturas tradicionales de organizarse en comunidades aldeanas. Un rasgo perfectamente campesino o propio de las sociedades campesinas que Parcero (1995: 130), siguiendo a Shanin (1983), considera uno de los principios claves que caracterizan a estos tipos de sociedades. Incluso autores como Rösener (1990: 65-67), que han estudiado el mundo campesino medieval, considera más evolucionadas las aldeas que las granjas aisladas, basando tal suposición en que los núcleos agrupados se constituyen cuando se produce una situación de nivelación social.

La posibilidad de asimilar esta otra unidad básica, la comunidad aldeana, de las sociedades campesinas tal y como la presenta Stirling (1979: 31), a nuestros castros debe pasar por su consideración como verdaderas comunidades. Es decir, esa comunidad que aglutina el recinto es un grupo social plurifuncional al que se pertenece por nacimiento o matrimonio. Lo que el autor citado denomina solidaridad campesina no sería otra cosa que lo que en el registro arqueológico de los castros hemos denominado complementariedad funcional de las unidades de ocupación.

Por otro lado, el carácter de comunidad que confiere al grupo su recinto amurallado, se complementa con otros mecanismos de afirmación que cumple la propia muralla. Nos referimos a la función que realiza hacia afuera. Los castros son elementos individualizados y destacados en el paisaje que actúan como marcas territoriales. No sólo eligen emplazamientos muy selectivos, en lugares altos y aislados, sino bien visibles. Ese factor de identificación del grupo, muy bien sintetizado por Criado (1993), permite su afirmación como comunidad frente a otras, en definitiva de un grupo aldeano autosuficiente frente a otros similares. Recordemos que estos castros nunca son muy amplios (rara vez superan las $2 \mathrm{Ha}$.) y suelen ser además todos del mismo tamaño.

Ese tamaño de cada comunidad castreña, su cohesión social doblemente reafirmada y su economía casi autárquica, concuerda muy bien con el modelo de aldea campesina que presentan la mayor parte de los autores que tratan sobre ese tipo de sociedades. Los habitantes del castro pertenecen a él de una forma más marcada que a cualquier otra estructura que conforme la sociedad a que pertenecen produciéndose lo que en ocasiones se ha denominado intensidad interna. De igual forma que hemos plan- teado que los individuos debían pertenecer a una unidad de ocupación, también pertenecían, en un determinado momento, a un castro. Algo que también plantea Díaz-del-Río (1995) al hablar de parentesco en este tipo de comunidades cerradas de la que no se suele salir más que para el matrimonio, entrando en ella de la misma manera; de tal forma que no se producen pérdidas en la fuerza de trabajo.

Se tratan pues de comunidades muy estables, ya no sólo en el sentido de la voluntad de permanencia que se refleja en su independencia territorial y, sobre todo, en la construcción de obras colectivas de cierta envergadura o en la fuerte relación con la tierra a que obliga su tipo de economía autosuficiente, sino en el sentido de la propia composición del grupo humano. También son estables en el sentido de que la mayor parte de los habitantes de un castro han nacido en él. De todo ello parece hacerse evidente que el intercambio para la reproducción social hacía qúe esas relaciones exteriores fueran más sociales que económicas, aspecto que es interesante desde nuestro punto de análisis de sociedad campesina. La razón está en que el intercambio económico entre castros debió ser mínimo. Todos producen -incluso en bienes de prestigio o de adorno personal- lo mismo y en cantidades similares. No parece que se tuviera un mínimo interés por intercambiar los mismos productos. La utilidad del intercambio parece estar más dentro de cada poblado que fuera de él.

Lo anterior concuerda con esa cultura material bastante inalterable o de cambios muy paulatinos que caracteriza a la Cultura Castreña del Noroeste. Aunque esos castros aislados y ese lento ritmo en los cambios materiales no nieguen la expansión de unas comunidades que van ocupando nuevas tierras al abrigo de cierta intensificación económica y un paulatino aumento demográfico. Mucho menos puede negarse el necesario intercambio entre asentamientos para la reproducción social que daría ocasión a una interacción entre comunidades bien patente en el registro arqueológico castreño.

En definitiva, la territorialidad de marcado carácter económico y unas relaciones entre asentamientos más sociales que económicas, son dos rasgos propios de las sociedades campesinas donde la vinculación a la tierra es necesaria, el intercambio mínimo y el mercado ocasional.

La seguridad, que se considera otro de los principios de la racionalidad campesina, aflora en algunos de los comentarios anteriores. De igual forma que el autarquismo y una sólida cohesión -a nivel 
de aldea- frente al exterior pueden considerarse dentro de los valores típicos del ideal campesino. Estamos pues ante una economía de subsistencia, cerrada, de base agropecuaria, en la que al no existir competitividad en la fabricación de otras manufacturas, al no existir lo que hoy llamaríamos mercado, la acumulación de excedentes es mínima o nula: el valor de la mayor parte de los productos no superaría, pues, lo que se denomina valor de uso (Vicent, 1991: 58-61).

Antes de terminar con este nivel de aldea y pasar a su obligada conexión con el tipo de territorialidad de estas comunidades castreñas, queremos siquiera mencionar una cuestión que se acomoda perfectamente a lo hasta ahora definido. Nos referimos a una de las fórmulas que utiliza la epigrafía indígena de época romana en el Noroeste para indicar el origo de las personas (González, 1986; Pereira, 1988; Beltrán, 1988). En efecto, la lectura social de la arqueología de estos castros parece concordar perfectamente, incluso obligar, a un tipo de fórmula como la que se resuelve en el corpus epigráfico de los castella: el origen de un individuo indígena no sería expresivo ni completo si no se indicase su pertenencia a un castro determinado, es decir, a su comunidad aldeana.Así, aunque se trate de unidades territorial y socialmente reducidas, su marcada independencia obliga a no prescindir de la denominación del castro y a relegar, por el contrario, la entidad social mayor a la que presumiblemente ese castro pertenecía. De igual forma que la sola filiación de linaje o parentesco parece ser considerada insuficiente para caracterizar a ese individuo.

\section{b) El territorio campesino de los castros}

Si los castros pueden presentarse como comunidades campesinas aldeanas debe ser factible encontrar indicadores de ese tipo de sociedad en su modelo de explotación del territorio. No en vano se trata de sociedades marcadamente territoriales. O dicho de otra forma deberíamos detectar en él un concepto propio de territorio campesino, parte inseparable de la aldea.

Ya hemos dicho que en la mayor parte de los estudios espaciales sobre la Cultura Castreña se acepta la ausencia de modelos jerarquizados (Carballo, 1993) hasta momentos muy tardíos, siendo los castros, independientes en el espacio, las únicas unidades sociales y territoriales reconocibles. También ha quedado establecido que estos núcleos en sus decisiones locacionales, es decir en la elección de sus emplazamientos, buscan tanto la visibilidad del asentamiento como la disponibilidad de un territorio productivo muy diversificado. De todo ello puede deducirse que estamos ante una agricultura tradicional de producciones también de gran variabilidad, es decir, que aprovechan un largo repertorio de recursos. El valle, los pastos, el monte, las tierras de labor, las necesarias materias primas... deben estar representados en sus inmediaciones (Fig. 6). Un paisaje productivo característico que cada castro busca antes que otro tipo o forma de relación territorial como pudiera ser la intervisibilidad, de tanto significado en los modelos jerarquizados precisamente, o una ocupación global del espacio.

En ese sentido, el territorio de cada castro proporciona al grupo una cohesión social similar a la que significaba el recinto, ya que es igual de excluyente que aquél. El espacio propio de cada asentamiento adquiere así un verdadero sentido de territorio demarcado, cuyo acceso corresponde a la comunidad cerrada que lo habita y es negado al resto. La independencia entre esos territorios aldeanos no se expresa, además, por su distanciamiento más o menos regular, sino por intervalos espaciales aleatorios. Algo que permite suponer que el territorio se acotaba mediante hitos, límites u otros marcadores espaciales -seguramente más naturales que artificiales, pero no menos efectivos-que determinaban un paisaje domesticado donde las comunidades se reconocían y eran respetadas por las demás.

En esa línea, podemos hablar de la existencia de un territorio propio y acotado de cada comunidad castreña. Es aquel que con una característica visibilidad permite ver desde el asentamiento la totalidad de su espacio productivo; en ese sentido tal visibilidad adquiere un significado más económico que social. Por otro lado, a la inversión colectiva de trabajo y tiempo que suponía la construcción de la muralla habría ahora que añadir la que se efectúa en ese territorio. Dos espacios, el de habitación y el de producción, que fijan y cohesionan al grupo social, territorializándolo. El resultado son esas comunidades casi autónomas, muy locales, donde se van acentuando por acumulación, los mecanismos de control y cohesión social.

Ilustrativa de los aspectos aludidos, que hacen de cada castro una comunidad territorial e independiente, puede ser una de las citas de Estrabón $(3,3,7)$ sobre los pueblos del Norte. Se trata de aquella que refleja la práctica de la lapidación a los parricidas 


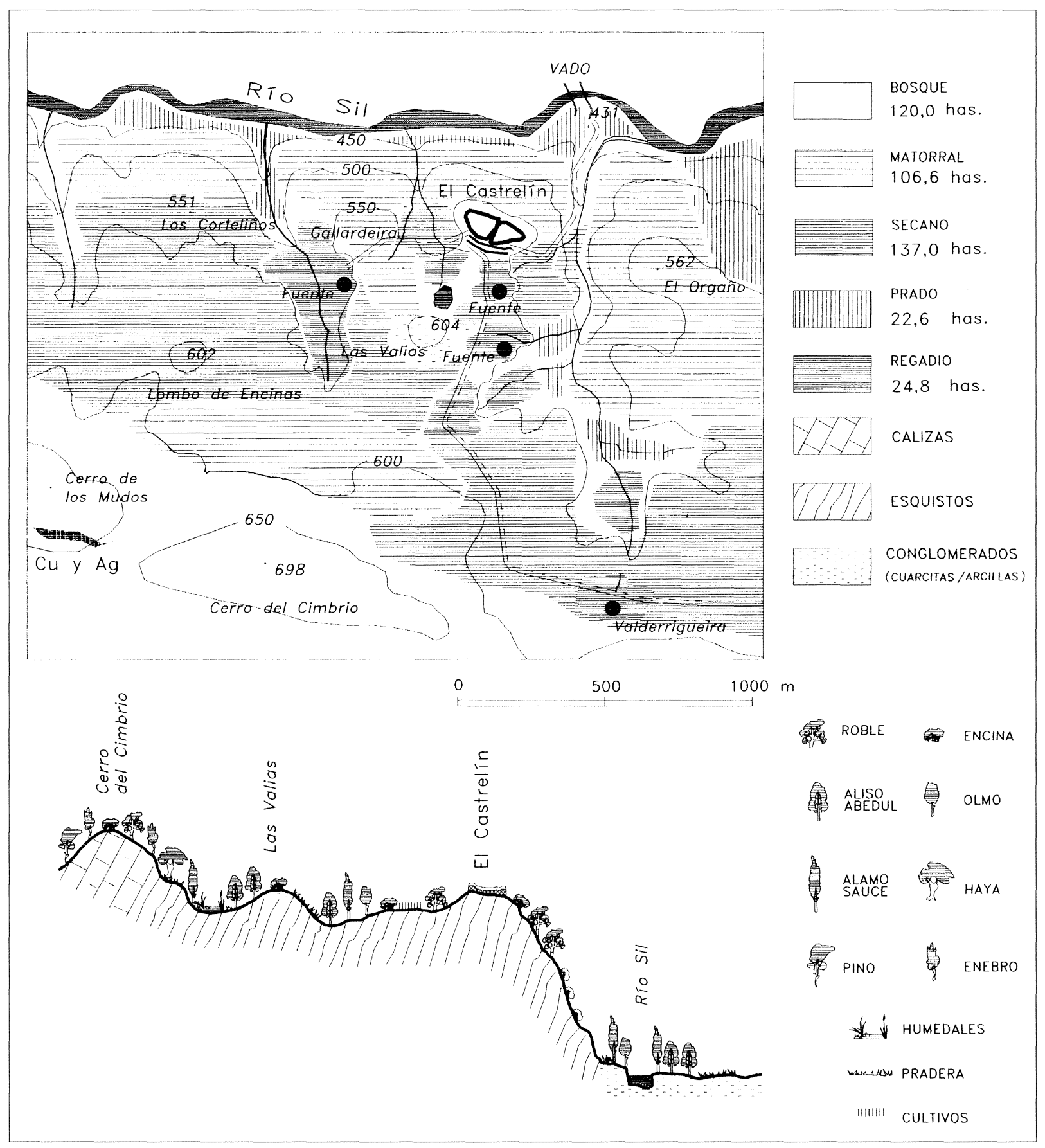

Fig. 6. Territorio de explotación de recursos de El Castrelín de San Juan de Paluezas y reconstrucción de su perfil a partir del registro polínico del yacimiento.

más allá de las montañas y los cursos de agua. Creemos que en ella están más o menos implícitas las características apuntadas: el máximo castigo es aplicado a aquellos que atentan contra la cohesión social del grupo, de un lado, y que este se hace efec- tivo de forma obligada fuera de los límites de su propio territorio, de otro. También en la misma cita se habla de la costumbre de exponer en los caminos a los enfermos con la finalidad de que puedan ser ayudados por otros que hayan sufrido males simi- 
lares. El camino parece ser, por tanto, un espacio geográfico periférico, neutro, en el sentido de que no pertenece a ninguna de las comunidades pero donde se asegura el posible contacto con individuos de varias diferentes.

La visión de ese territorio es, sin embargo, tan vaga en nuestro caso como en el de Estrabón. Hemos hablado de límites materiales aunque por el momento nada permite ir más allá de la notoriedad física de ciertos elementos geográficos -sierras, pasos, ríos, vados...- sugerentes en los castros leoneses de un paisaje cerrado en torno a los dominantes asentamientos. A este respecto puede resultar productiva la línea de trabajo abierta por el Grupo de Investigación de Arqueología del Paisaje de la Universidad de Santiago de Compostela en el estudio tanto de la dimensión simbólica del espacio como de la racionalidad con que las comunidades castreñas lo pensaban y conceptualizaban, con elementos formales tan concretos como la monumentalización y visibilidad de los asentamientos y las líneas de tránsito (Criado, 1992, 1993; Parcero, 1995; Santos et alii, 1997). Por más que no podamos menos que diferir del modelo jerarquizado que se propone en esos trabajos y consideremos por tanto discutible su concepto de paisaje cóncavo, sea en la escala de valle o de sector de valle. De igual forma que encontramos abusivas algunas extrapolaciones entre territorios castreños, medievales y parroquias actuales. Tales generalizaciones históricas, que presentan una inaceptable y nada comprobada continuidad entre el espacio agrario protohistórico y la Galicia tradicional actual, presentan un territorio castreño con unidades productivas separadas, nítidamente compartimentadas en bosque, valle cultivado, pastos e, incluso, ribera fluvial, tal y como en la actualidad se ordenan en torno a las aldeas rurales; incluso, se señala como los castros quedan situados en el límite de terrenos cultivados e incultos.

En nuestra opinión las muy abundantes unidades productivas castreñas, como corresponde a su base económica muy diversificada, se engloban y mezclan en un mismo territorio. Estaría más cerca del esquema de lo que Díaz-del-Río (1995: 106) denomina estrategia agroforestal y, sobre todo, se adapta a la reconstrucción del espacio de captación de recursos de El Castrelín que, en base al registro paleoecológico, quedó reflejada en la ya citada figura 6. Parcelas de diferentes cultivos, bosque y pastos mejorados, matorral, huertas, etc, así como las fuentes de materias primas para útiles líticos y metálicos, colorantes, etc se encuentran de manera deliberada mezcladas en una amplia y única unidad de producción y gestión de recursos que es, además, visible desde el asentamiento en todos sus componentes.

Ambos aspectos, los significantes espaciales que afirman la identidad del territorio de un castro frente a otros y ese peculiar espacio productivo donde todos los recursos interaccionan y están a la vista, concuerdan cabalmente con la racionalidad campesina cuyos objetivos de seguridad y de minimización de riesgos pasan por encima de la rentabilidad o la especialización en la modificación y gestión del medio natural.

Ese paisaje de aldeas diseminadas, donde parece primar el ideal autárquico y las fronteras tanto físicas como sociales nunca son vagas, puede calificarse de campesino. Pero en este punto es donde se rompe nuestro discurso llevado hasta el momento de forma relativamente cómoda. En efecto, los cuatro niveles analizados hasta ahora-los almacenes, la unidad doméstica, el castro y su territorio- permiten plantear de forma razonable que las comunidades prerromanas de la zona galaico/leonesa tenían la estructura de una sociedad campesina. Sin embargo, la mayor parte, por no decir la totalidad, de los estudios sobre ese tipo de sociedades consideran que el motor de su modo de vida no es sólo su subsistencia, sino el poder político y económico. Se plantea pues la necesidad de una instancia superior capaz de exigir tributos. Aunque se aduzca, en este caso, que también la totalidad de esos estudios están realizados lejos de contextos arqueológicos, el problema queda planteado: las sociedades campesinas requieren para serlo la existencia de un poder estatal o de una dicotomía campo/ciudad. Eso es algo que el registro arqueológico de la Cultura Castreña no sólo no refleja sino que, por el momento, contradice.

No somos, sin embargo, los primeros ni los únicos en encontrar esa dificultad. De una manera genérica Díaz-del-Río (1995: 104-105) especifica que en una auténtica comunidad campesina debe haber grupos dominantes que extraen y se apropian del excedente, aunque luego matice a la baja esa afirmación. De hecho es difícil superar el universal de que estas etapas protohistóricas se caracterizan por una centralización de las actividades redistributivas. Así lo cree Parcero (1995: 129) cuando admite esa subordinación obligada del campesinado a redes más altas de poder. No obstante pese a que este autor, como Criado, admite un poblamiento jerar-

T. P., 55, n. ${ }^{\circ} 2,1998$ 
quizado para la Cultura Castreña, no llega a establecer el modelo. Es decir, ni a nivel del asentamiento ni en el territorio demuestra esa estructura jerárquica necesaria. De hecho hasta momentos muy tardíos y sólo en determinadas zonas no puede entreverse ese modelo jerarquizado con núcleos mayores capaces de acaparar ese excedente.

Esa falta de un poder estatal o de, al menos, una jerarquía dominante, de la existencia, en definitiva, de obligaciones de cada comunidad castreña dentro de un sistema económico más amplio donde hay no/campesinos, no se documenta por el momento en la arqueología castreña; ni siquiera en el grado poco patente que algunos autores dan a la presencia de ese poder superior, que ejerce de forma irregular su exigencia tributaria o impositiva, en los medios campesinos más tradicionales.

Debemos por lo tanto dejar planteado como problema la existencia de una unidad económica a ese nivel supracastro, cuya existencia en ningún modo negamos pero que el registro arqueológico no deja afirmar, para entrar en otros temas no menos importantes cuando se estudian sociedades campesinas antiguas. Nos referimos a cuestiones y conceptos como subsistencia, nivel tecnológico, tierra y propiedad.

\section{LA TIERRA Y LA ORGANIZACIÓN SOCIAL DEL TRABAJO}

Hasta aquí hemos tratado de hacer una lectura campesina de la información proporcionada por los castros prerromanos de la ZAM y ha quedado en evidencia que varios aspectos de la estructura social que reflejan los datos del registro concuerdan con ese tipo de sociedad. Pero tal caracterización nos lleva de forma inevitable a contenidos, hasta ahora aludidos puntualmente, que permitirán matizar lo expuesto. Por ejemplo, sólo de forma colateral hemos afirmado la vinculación directa que en las sociedades campesinas debe existir entre la unidad doméstica y la tierra. Ella es, junto con los miembros de esa unidad entendidos como fuerza de trabajo, su medio de producción. Tanto su subsistencia como su seguridad, en definitiva su existencia, dependen pues de sus derechos sobre esa tierra o sobre su explotación.

La formulación del párrafo anterior plantea de forma automática dos problemas. El primero, más obvio, es la posibilidad de objetar que las sociedades poco o escasamente complejas que viven de la tierra son todas campesinas, dada su base mayoritariamente agraria; por lo menos en el sentido de su necesidad de disponibilidad y apropiación de la tierra. Generalización incluso más fácil de realizar en aquellas comunidades en las que en su economía, siempre cercana a la subsistencia, lo pecuario se encuentra ligado a lo agrícola sin la tópica contraposición de ambos sectores.

Sin embargo, una sociedad campesina va más allá de esa subsistencia basada en la producción agrícola. En primer lugar está esa peculiar familia campesina, unidad social y núcleo económico de una no menos especial estructura aldeana. El castro, en cuanto que verdadera comunidad plurifuncional, es una determinada forma social. En segundo lugar está su propio modelo de explotación económica, un tipo específico de economía agraria compleja y evolucionada a la que se añade la denominada racionalidad campesina. Ésta, con el objetivo de una seguridad en cierto modo conformista, es la que provoca la tendencia a la diversificación más que la intensificación de la producción. El resultado es una pluriactividad -en la que tienen cabida gran cantidad y diversidad de productos de la recolección- mucho más variada que la de otras comunidades que viven de la agricultura y, por lo tanto, una no/especialización en la maximización del recurso más apropiado o rentable. Su proximidad a la subsistencia no depende pues de factores externos o tecnológicos, de la disponibilidad o potencialidad de un determinado recurso, sino de su propio modelo de explotación económica.

El segundo problema es cómo se plantea, en el caso de las comunidades campesinas, su relación con la tierra. Es decir, a que escala y de que manera se ejerce la tenencia de los derechos sobre ella. Se pueden objetar, en este caso, que más que un problema de posesión, de propiedad privada, lo que puede existir es una apropiación de la tierra por la comunidad que permite su explotación. En definitiva da igual que se hable de derechos de propiedad, de uso o de usufructo. En el caso de las comunidades castreñas leonesas es factible detenerse en ese punto, sobre todo si se tienen en cuenta las bajas densidades de castros y, por tanto, la escasa competencia por los recursos.

\section{a) La propiedad y el uso de la tierra}

En un oportuno y reciente trabajo, Gilman (1997) se extiende precisamente sobre estas cues- 
tiones de propiedad de la tierra y sus indicadores en el registro arqueológico, señalando como incluso en el momento más optimista de la arqueología procesual fue un tema poco o nada atendido. Sin embargo, deja claro que, pese a sus dificultades, es del máximo interés en el planteamiento de las relaciones económicas de las comunidades prehistóricas y abre algunas líneas para su estudio.

En el mundo castreño, como en otros grupos culturales prerromanos, ha sido un tema abordado exclusivamente desde la lectura de ciertos textos clásicos, como algunos pasajes de Estrabón sobre matriarcado y herencia $(3,4,18)$ o el que se refiere a la existencia de una supuesta práctica colectivista agraria entre los vettones de la Meseta (Salinas, 1986: 46), muy citado en la literatura de todo un siglo para los pueblos de la llamada Hispania céltica y en el que se apoya la asunción de que la propiedad de la tierra debía ser comunal y la de los ganados, como expresión de riqueza, privada. Aún así, el texto de Julio Frontino en que se basa menciona simplemente un tipo de campo de propiedad indivisa existente en unas ciudades concretas. El ambiente ciudadano en que tal información se da, su parcialidad y la aventurada extrapolación a todo el norte peninsular, nos dice que estamos ante generalizaciones nacidas en el seno de los estudios sobre instituciones de la etnografía antigua.

Coincidiendo con Gilman en el interés del tema desde una perspectiva arqueológica, diremos que en una lectura lineal o simplista del registro doméstico de La Corona y de El Castrelín pudiera llegar a pensarse que si cada unidad de ocupación o, lo que es lo mismo, cada familia, es propietaria de un almacén y por tanto de la cosecha que éste alberga, lo sería también de la parcela que la produjo en el territorio del castro. Un almacén privado indicaría una tierra propia o de propiedad privada. Se cumpliría así de forma ajustada la necesaria vinculación de la unidad productiva con su medio de producción que se exige en la estructura de las sociedades campesinas. Pese a ello, sólo podría afirmarse que la cosecha pertenece a la unidad familiar en el almacén, donde es realmente suya y le asegura la subsistencia. No puede afirmarse lo mismo de la propiedad de la tierra.

Por otro lado, parece seguro que de igual forma que una comunidad castreña levanta de forma común el recinto que la identifica como grupo social, se apropia de la tierra que constituirá su territorio. Territorio, por otra parte, tan cuidadosamente elegido como el emplazamiento. Adscrita de esta for- ma la tierra a la comunidad, no sería difícil imaginar que siga siendo el propio castro - expresión fisica del grupo-quien la administre. Si se admite la muralla como una inversión del trabajo colectivo, ese territorio de producción demarcado puede ser en definitiva igual de colectivo en inversión y en propiedad.

Vemos que es fácil argumentar las dos cosas: la propiedad privada de la tierra basada, entre otras cosas, en la forma de almacenaje o la colectiva basada en los fuertes lazos sociales de la comunidad y su aparente ausencia de jerarquización. Sin embargo, hay algunas otras cuestiones a tener en cuenta. La primera es esa forma social de familia campesina, tan cerrada e independiente dentro de ese recinto colectivo. Sus derechos de usufructo sobre la tierra deberían pues estar más cerca de la propiedad familiar que de un uso colectivo regulado por la comunidad. Por lo menos en aquellas parcelas productivas dedicadas al cultivo. Debemos tener en cuenta, como recuerda Gilman (1997: 84) en el trabajo citado, que un campesino del siglo XVII combinaba el trabajo en sus propias tierras con arrendamientos y explotación de derechos comunales en otras. Es decir, la variabilidad de derechos sobre la tierra se corresponde con el tipo de recurso que en ella se explota. Algo fácil de suponer en el diversificado territorio de los castros, donde parcelas de bosque y matorral mejorados y pastos debieron ser comunales. Es, por tanto, plausible proponer diferentes sistemas de propiedad para diferentes espacios productivos.

Una segunda cuestión sería el propio registro constructivo, es decir, la organización, ahora desde una perspectiva general, del espacio doméstico en el recinto del castro. A este respecto también viene al caso otro de los ejemplos utilizados por Gilman, tomado de un reciente estudio de Bernbeck (1995), en el que se atribuye mayor distancia social, tanto dentro de cada poblado como entre poblados, a aquellos asentamientos donde los recintos familiares son grandes y utilizan técnicas constructivas elaboradas, los almacenes están en su interior y los poblados se fortifican que en aquellos otros donde el almacenamiento es comunal, los espacios públicos superan en importancia a los privados y están sin fortificar. Parece claro que los castros leoneses pertenecerían al primer modelo. Sin embargo, la inutilidad como tal modelo para deducir un determinado sistema de tenencia de la tierra en los castros leoneses no proviene de que Bernbeck y Gilman hablen de culturas de la Mesopotamia del VI 
milenio ANE, sino del medio árido donde se desarrollan, en el que la necesidad o no del regadío para alcanzar la subsistencia hacen de la tierra un medio de producción más valioso que en climas como el del Noroeste peninsular. Por otro lado, el propio Gilman (1997: 87) señala con acierto la resolución diferente que, en términos evolucionistas, podría haber tenido tal modelo con la puesta en marcha de mecanismos de intensificación de la organización comunitaria para evitar el paso a la desigualdad basada en la propiedad de más y mejores tierras.

Es evidente la existencia en los castros de ese tipo de mecanismos que promocionan o refuerzan la solidaridad y la cohesión del grupo como tal y que, por encima del almacenaje privado o la falta de espacios públicos, frenarían la aparición de desigualdades en el acceso a la tierra o las regularían. Pero quizás la cuestión que más puede ayudar en el caso de las comunidades castreñas es el tamaño de la comunidad en relación con esa contención -O deliberado límite- de su producción que hemos analizado ya en el registro constructivo en apartados anteriores. Nos referimos a ese buscado equilibrio producción/consumo donde es menos que imposible separar inversión, costes y renta y donde el excedente apenas tiene presencia. Eso significa, desde el punto de vista económico, un mantenimiento casi constante del tamaño del grupo, sus recursos disponibles y el nivel tecnológico y, desde el punto de vista social, una estructura muy cercana, al menos en algunos aspectos, a la de una sociedad segmentaria donde un crecimiento demográfico o un descenso de los recursos provocaría la fisión del grupo y el establecimiento de un nuevo castro.

Las indudables connotaciones de funcionalismo ecológico del párrafo anterior quedan paliadas en el contexto de la racionalidad y comportamiento campesino, pero es evidente su necesidad de explicación.

\section{b) El espacio agrario diversificado propio de una economía campesina}

Ya hemos dicho que estos castros leoneses presentan unas dimensiones similares y que albergaban a grupos que rara vez sobrepasan las 200 personas; algo perfectamente extrapolable a los de clara adscripción prerromana del conjunto de la Cultura Castreña (Carballo, 1993). Tomaremos como ejemplo el Castrelín de San Juan de Paluezas, cuyo te- rritorio de explotación se ha determinado mediante un radio de $2 \mathrm{~km}$. aproximadamente en torno al asentamiento, corregido por un estudio de su cuenca visual, definida a su vez por las alturas y pasos naturales más próximos. Como se ve en la figura 6 , el territorio de explotación resultante es de más de 400 Ha. para sus 120/160 habitantes. Las tierras productivas de este castro se sitúan, contrariamente a lo que podría suponerse, al sur y no en el fértil valle del río Sil que corre a sus pies. Ese tipo de terrenos de valle profundos y fácilmente inundables tienen todas las dificultades para el nivel tecnológico de estas comunidades poseedoras de un arado superficial que no voltea la tierra. Eso no excluye la presencia ocasional en ese sector de algunas parcelas de cultivo y que tales terrenos, donde se sitúa uno de los vados históricos que cruza el río, no fueran aprovechados para captación de recursos tal y como indica el registro paleoecológico. Pero para su espacio agrario, su terrazgo, los habitantes de El Castrelín preferían las tierras más altas, ligeras y aireadas de la zona meridional más próxima y accesible desde el poblado, conformada por suaves colinas donde son frecuentes las fuentes y las pequeñas arroyadas pero donde el drenaje quedaba asegurado. Allí podía cultivarse un secano viable con producciones que podemos estimar, si nos permitimos extrapolaciones históricas, como las de fuentes inglesas medievales manejadas por Rösener (1990: 144), de 1/3 o 1/4. Esto supondría unas $5 \mathrm{Ha}$. por familia si repartimos las potenciales 137 entre el número de unidades de ocupación. Más que suficiente teniendo en cuenta los datos del autor citado que sugiere una media de $4 \mathrm{Ha}$. por familia, cuando no son dimensiones condicionadas por unidades tributarias. Junto a ese cereal de invierno está documentada la introducción del mijo, cereal de verano. Esta presencia no responde a su mayor rentabilidad, como aseguran algunos autores, o al alcance de un recién logrado nivel tecnológico que permiten el cultivo de tierras más profundas y pesadas, como sugieren otros. Su presencia corresponde al objetivo de cubrir riesgos -compensaría una mala cosecha de invierno- y concuerda con la diversificación del espacio productivo; es decir, estamos una vez más ante la racionalidad campesina. El mijo, en efecto, no necesita arado, es poco exigente y se trata en realidad de un cultivo de casi huerta que se trabaja con azada. En el territorio de explotación del Castrelín ocuparía un característico tipo de espacio muy cercano y visible desde el poblado. Se trata de terrenos llanos o aterrazados en las inmediaciones de fuen- 
tes o cabeceras de arroyos que hoy son prados cerrados o parcelas plantadas de castaños. Esa abundancia de zonas húmedas permitía también el establecimiento de huertas y prados mejorados, así como el desarrollo de cultivos específicos como el lino. Su extensión y dispersión, mayor en la documentación proporcionada por los análisis polínicos que en la actualidad, permiten una cifra cercana a la hectárea por familia.

Haremos notar que el margen de disponibilidad de los dos tipos de terreno de cultivo, el que acabamos de describir y el de secano, permitía un régimen de barbechos amplios, de dos o tres años, a añadir a la indudable función que en la recuperación de las tierras cumplía el abono animal. Lo que ya no parece tan asumible es la existencia entre estas poblaciones de cultivos de roza propuesta por autores como Parcero (1995: 132), apoyada en un supuesto primitivismo de la actividad agrícola en la Cultura Castreña que no se corresponde con la realidad. Sigue, en este punto, la línea de la historiografía castreña en la que hasta no hace tanto se mantenía una escasa y poco evolucionada actividad agraria (Carballo, 1993) y un predominio del pastoreo (Martíns y Jorge, 1992), que en definitiva son herederas de las tópicas e interesadas informaciones proporcionadas por los textos clásicos sobre estas poblaciones. Basta recordar la cita de Estrabón sobre la fuerte presencia de la bellota en su dieta $(3,3,7)$.

Sin embargo, es precisamente esa negación de la agricultura cerealística, como prueba para los autores clásicos del primitivismo de estos pueblos y orientada en sentido contrario a su interpretación habitual, la que refleja la importancia y el peso de las actividades recolectoras entre estas comunidades campesinas y la diversificación de recursos de su sistema económico.Algo que queda bien patente en las más de $200 \mathrm{Ha}$. de bosque y matorral -que muchas veces debieron estar mejorados- con las especies cuya presencia documentan en El Castrelín la antracología y el polen. Espacios productivos que permitían también la recolección y almacenaje de forraje encaminado a la alimentación invernal del ganado estabulado y a la producción de estiércol o abonos.

Estos métodos de explotación -que hemos de suponer permitían llegar no mucho más allá de los mínimos existenciales- se apoyan como es lógico en una serie de instrumentos de cultivo cuya efectividad proviene de la utilización del hierro de forma masiva. Aunque no son demasiadas ni bien con- servadas las herramientas de ese tipo recuperadas en los castros, el volumen de fundición que atestigua la cantidad de escoria recogida tanto en La Corona como en El Castrelín permiten hablar de una producción constante. Sobre todo en este último poblado de ocupación más larga donde la escoria y los restos de fundición de hierro - entre los que destacan varias esponjas de fondo de horno- recogida en los niveles excavados se cifra en más de $300 \mathrm{~kg}$. de escoria. Siempre teniendo en cuenta que la manufactura de útiles nuevos sería, en comparación a la del mantenimiento de los ya en uso, la labor menor del metalúrgico que, desde ese punto de vista, justifica su condición de artesano a tiempo completo. La materia prima necesaria para esa producción, próxima y de fácil extracción, debe asociarse también a las beneficiadas mineralizaciones de cobre y plata que los estudios arqueometalúrgicos han demostrado son la fuente de aprovisionamiento de El Castrelín (Fig. 6). No menos próximas al asentamiénto se encuentran otro tipo de materias primas, como la cuarcita o las arcillas utilizadas para la fabricación del instrumental doméstico -útiles líticos y vasijas cerámicas - o en la construcción, como puede observarse en la figura citada.

Nos referiremos, por último, al ganado. Pese a un sinfín de generalizaciones, basadas también en los textos literarios y en la corriente historiográfica propia de la Cultura Castreña, que ven en la ganadería significados simbólicos y la ligan a un especial tipo de riqueza móvil o actividades como el bandolerismo y el pillaje, la cabaña de El Castrelín es perfectamente doméstica. Así lo atestiguan los análisis faunísticos que la presentan compensada, bien acondicionada al paisaje y al clima, evolucionada y, sobre todo, orientada a los productos secundarios como la leche o la lana. En esa cabaña el caballo y la caza-especie y actividad siempre citadas como importantes entre estas comunidades del Norte-demuestran, por el contrario, su escasa incidencia. Por otro lado, los basureros, en algunos casos atribuibles a determinadas unidades de ocupación, muestran una considerable similitud en volumen y especies aprovechadas en la dieta de todos lo grupos familiares.

Esta cabaña tan campesina actúa en una perfecta simbiosis con la producción y el espacio agrícola. Y de ambas, por una sobreexplotación más o menos coyuntural, es fácil explicarse la extracción de un excedente que permite acceder a cada familia al intercambio de útiles y herramientas, a pequeños objetos de adorno personal o a intercambios socia-

T. P., 55, n. ${ }^{\circ} 2,1998$ 
les de regalos, matrimonios, dotes, etc en un tipo de mercado tan ocasional como la producción del propio excedente.

Todo lo anterior deja claro que la relación población/recursos era viable en El Castrelín y posible el mantenimiento del equilibrio entre ambos factores, siempre que no se produjera un extraordinario crecimiento demográfico o una catástrofe medioambiental. Pero junto a la configuración física del espacio productivo, los métodos de explotación y el nivel tecnológico, existe un cuarto factor no menos importante: la organización social del trabajo.

\section{c) Una estructura social compleja de escasa organización formal}

La fuerza de trabajo la constituían, ya lo hemos dicho, los miembros de cada unidad de ocupación o grupo familiar, unidad de producción que refleja el registro arqueológico de los castros y que es característica de las sociedades campesinas. Su independencia económica basada con probabilidad en la posesión de determinadas parcelas de cultivo y en el aprovechamiento de los recursos de otras explotadas en régimen comunal dependía, sin embargo, de la comunidad castreña. Es decir, es la pertenencia a esa comunidad social la que permite a cada familia el acceso al insustituible medio de producción que es la tierra. Volvemos pues a encontrar -como en la estructura interna del poblado- dos fuerzas contrapuestas: la autosuficiencia de las familias y la comunidad castreña como estructura de poder que ejerce la coerción en la organización social del trabajo. Porque, en definitiva, debe ser esa estructura aldeana quién prescribe tipos y formas de cultivo, determina los límites de la producción o regula el excedente, rige las formas colectivas de explotación de pastos y bosque, establece la complementaridad de las producciones, etc, además de adjudicar la propiedad o el uso de la tierra.

Esa autoridad organizativa de la comunidad no era el ambiente más propicio para la creación de jerarquías si atendemos a los mecanismos e indicadores más utilizados para medir el grado de complejidad social. Pero no es descartable que la tierra en propiedad fuera susceptible de herencia y existieran sutiles diferencias entre esas parcelas privadas $\mathrm{y}$, por lo tanto, producciones algo mayores. Eso no impide que en general pueda considerarse que el acceso a la tierra nunca debió ser demasiado desigual. Eso, junto con la escasa incidencia del exce- dente en las relaciones económicas, deja a estas comunidades de los castros fuera del esquema evolucionista que se presenta en el citado trabajo de Gilman (1997: 83-84). La estructura social de estos castros no estarían, por tanto, en el estadio de tribus o jefaturas de esa escala, sino que su organización quedaría fuera de ella por su tipo especial de economía campesina.

Hay dos cosas en los párrafos anteriores que merecen una particular atención. La primera es el papel que en estas comunidades castreñas tiene la mujer; la segunda es si tenemos suficientes datos para hablar de jefaturas no/económicas.

Es bien sabida la existencia en la etnología de estas comunidades castreñas de una larga discusión sobre la posible configuración de una suerte de matriarcado y, sobre todo, de una valoración importante de la participación de la mujer en la vida de la comunidad. Una vez más tales ideas se basan en algunos pasajes de Estrabón sobre los pueblos del Norte peninsular. González, en un trabajo específico sobre este tema de 1993, matiza bien hasta donde es posible hablar de matriarcado. Y el recorrido es bien corto. Pues si es cierto que el autor citado $(3,4,18)$ registra que son las mujeres las que heredan, no dice qué (tierras, privilegios,...) y, por otra parte, la filiación de la epigrafía indígena de época romana, es siempre patrilineal. Sin embargo, la autora hace hincapié en ese destacado papel de la mujer en el ámbito familiar y en la vida económica de la comunidad, uno de cuyos apoyos es el aserto del geógrafo griego de que eran las mujeres las que se dedicaban a la agricultura, por más que González (1993: 54) deba reconocer finalmente que el poder político está en manos de los hombres. La realidad parece haber sido otra. El supuesto protagonismo de la mujer en un sector básico como es la agricultura no parece ser otra cosa que su carácter de fuerza de trabajo de la unidad familiar en las economías campesinas. Es decir, no habría que confundir esa indudable importancia de la mujer en una unidad de producción, consumo y reproducción como es la familia campesina, con su acceso a la estructura de poder. Son los hombres los que en otro pasaje estraboniano $(3,3,7)$ ocupan puestos según su edad o dignidad en fiestas o comidas colectivas dentro de las comunidades aldeanas. Estos banquetes, a los que suele atribuirse una finalidad de refuerzo político o valor cohesivo en las estructuras gentilicias de parentesco real o ficticio, nos llevan al segundo punto: el tipo de jerarquización o grado de complejidad social de estas sociedades castreñas. 
Hemos visto como la comunidad castreña, aunque no controle directamente la fuerza de trabajo de cada unidad familiar, actúa como una instancia social de poder, generada, en principio, a partir de necesidades de cooperación económica del grupo como tal. Su expresión son determinadas obligaciones colectivas, contenidas en un derecho local -el que reflejan las citas de Estrabón-, que permiten plantear la existencia de caracteres propios de una comunidad política, institucionalizados aunque no totalmente desarrollados. También hemos visto como esa estructura de poder se organiza, además de por edad, por jerarquías basadas en el rango y la dignidad, es decir, aparentemente sin significación económica o no basadas en la riqueza. En ese contexto es fácil atribuir un estatus superior a individuos que han realizado algo a favor de la comunidad y aún más fácil considerar que ha sido llevado a cabo en el campo de la guerra. Con esto llegamos a otro de los lugares comunes de la historiografía gallega, sobre todo en autores como Criado (1991) o Parcero (1995) que suelen afirmar la existencia de las dos vertientes, campesina y guerrera, en la sociedad prerromana, aunque nunca lleguen a explicar su articulación. Este componente guerrero, que suelen calificar de heroico, se sigue bien en la tradicional e insuficiente lectura bélico/defensiva de su tipo de asentamiento, en la pertenencia de estas comunidades a un fondo poblacional indoeuropeo o celta, $o$ desde la narración ideologizada de los textos antiguos que las presentan como pueblos bárbaros dedicados al pillaje (García Quintela, 1993). Igualmente es de fácil asunción desde la interpretación de determinadas divinidades asociadas a la guerra (García, 1990, 1993) o a partir de la trasposición desde otras culturas de organizaciones tipo fratrías de jóvenes guerreros (Bermejo, 1986) o de aristocracias basadas en la guerra. Pero es mucho más difícil verlo desde la arqueología. Aun así es evidente que un sector minoritario de estas comunidades hubieron de ocuparse de defender colectivamente su territorio y que de forma esporádica debieron surgir líderes carismáticos que consiguieran formar partidas, pero la falta de objetivos, ideología y estabilidad, unidos al tipo de economía, debieron reducir esta actividad a algo meramente ocasional.

La escasa organización formal que parece inherente a la actividad guerrera entre estas comunidades es en cierto modo extensible al resto de su estructura social. Pero el hecho de no reflejar desigualdades o, dicho de otra forma, la aparente igualdad en el modo de vida dentro de estas comunida- des, no excluye la alta significación social que pudieron alcanzar determinados individuos dentro de su estructura social. De hecho parece seguro que algunos de esos jefes de comunidad consolidaron su poder, institucionalizándolo. Serán los que, integrados a través de determinadas formas de dependencia, actuarán de interlocutores para los intereses romanos en la zona (Sastre, 1998: 50-52).

A este respecto hay que decir que la caracterización de estas comunidades indígenas encuentra su necesario contrapunto en la presencia romana. Como dijimos al inicio del trabajo su estudio se integra en un proyecto cuyo objetivo es precisamente el conocimiento de las transformaciones que esa presencia provoca en dichas poblaciones que son reorganizadas, como lo es el territorio y sus recursos, en función de una nueva actividad económica: la minería del oro a gran escala. Tales cambios y rupturas en la sociedad prerromana quedan perfectamente ilustrados en el tema que es objeto de este trabajo. Las comunidades pierden paulatinamente la estructura social de aldeas independientes y economía campesina y se integran en patrones organizativos más amplios y complejos viéndose obligadas a participar en el sistema creado en torno a esa minería.

Las poblaciones se reorganizan en un patrón de asentamientos, mucho más numerosos pero de menor tamaño, complementarios y funcionalmente diferenciados que explotan intensivamente no sólo el oro sino el resto de los recursos. En ese sistema el sector agropecuario conserva, como es lógico, su importancia, pero la producción se organiza de una forma totalmente diferente. La explotación se llevará a cabo en pequeñas granjas que se diseminan en los terrenos abiertos y de mayor rentabilidad cercanos a la gran mina de Las Médulas o en castros de claras tendencia agrícola y ganadera jalonando los canales que abastecían de agua a las explotaciones. Uno y otro tipo de asentamiento cumplen con la función de abastecer a toda la población involucrada en la minería, tanto la que cumplía con labores de mantenimiento de la infraestructura hidráulica como la que se dedicaba a producciones especializadas como la metalurgia. Parece claro que aún siendo una producción importante ya no estamos ante una sociedad campesina. Estos campesinos de época romana ya son una sociedad parcial dentro de un sistema global que, con un nuevo orden político y económico, diluye su estructura social anterior. Un ejemplo evidente de esos cambios podemos verlo en la figura 7 . 


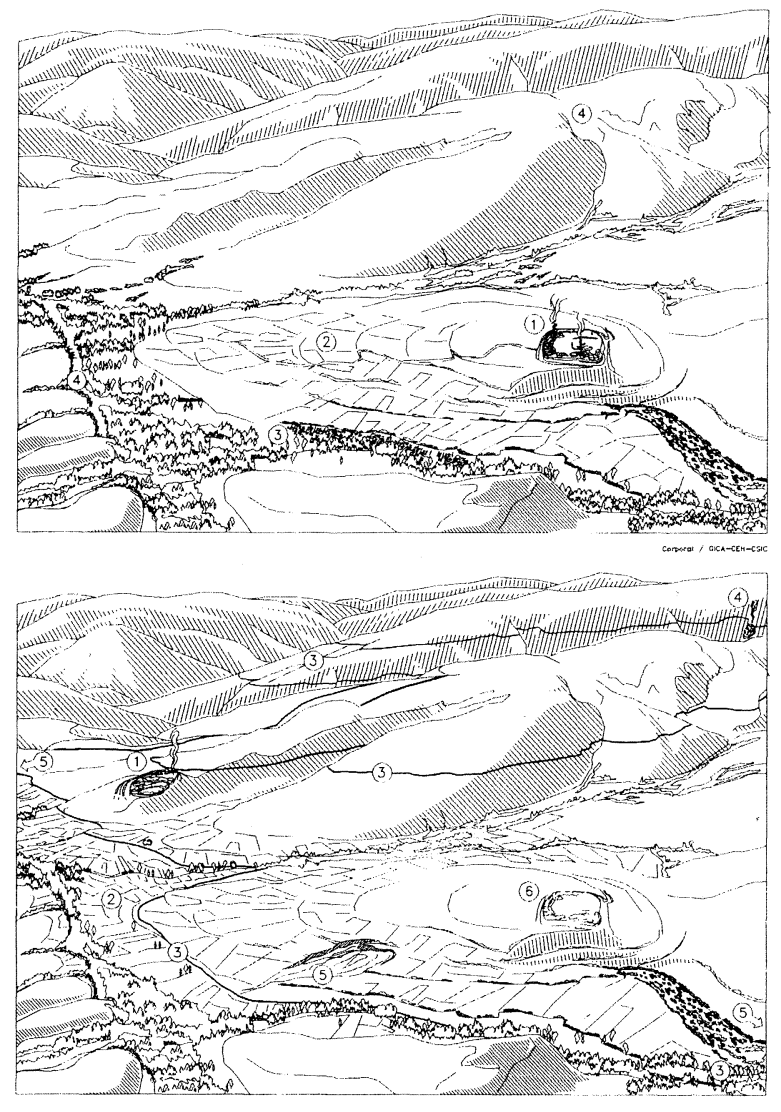

Fig. 7. En la ilustración superior: Castro prerromano de La Corona de Corporales. El asentamiento (1) y sus recursos: tierras de cultivo (2); aprovechamiento de la vega (3) y del monte (4). En la ilustración inferior: Castro romano de Corporales. El asentamiento (1) y sus recursos: tierras de cultivo (2); canales de conducción de agua a las minas de oro (3); explotación del monte (4); minas de oro (5); asentamiento prerromano destruido y abandonado (6).

Entre los mucho indicadores arqueológicos de esta ruptura está la estructura interna de los asentamientos, sean castros o no, en la que desaparecen las unidades de ocupación. Su complementariedad económica cambia de escala y pasa a ser comarcal o regional, es decir, deja de manifestarse en los asentamientos plurifuncionales para hacerlo en el territorio. Los recintos de esos castros, pese a su pervivencia como tipo de asentamiento, pierden su significado social. Puede servirnos de ejemplo la factoría metalúrgica de Orellán, donde el poblado se dedica mayoritariamente a esa producción y es abastecido, como prueban los almacenes colectivos, por aquellos asentamientos de tendencia agrícola o ganadera. En definitiva, la incorporación de las comunidades campesinas prerromanas es con- trastable a tres niveles: en el económico, en el que se pasa desde el reducido grupo familiar hasta la empresa industrial de las minas romanas; en el nivel estructural, desde las comunidades aldeanas marcadas por la insularidad a la participación en una sociedad de clases; y en el nivel cultural, desde la diversidad de esos castros independientes a la homogeneidad romana.

\section{BIBLIOGRAFÍA}

Agrafoso Pérez, X. (1989): O povoamento castrexo na rexión occidental da provincia da Coruña. Santiago de Compostela.

Aira Rodríguez, M.J. (1996): "La vegetación gallega durante la época de la ocupación romana a través del estudio del polen fósil". En Lucus Avgusti. F. Pedro Barrié de la Maza. La Coruña: 25-45.

Aira Rodríguez, M.J.; SaA Otero, P. y Taboada Castro, T. (1989): Estudios paleobotánicos y edafológicos en yacimientos arqueológicos de Galicia. ArqueoloxíaInvestigación, 4. A Coruña.

Bermejo, J.C. (1986): Mitología y mitos de la Hispania prerromana 2. Ed. Akal. Madrid.

BERNBECK, R. (1995): "Lasting alliances and emerging competition: economic developments in early Mesopotamia". Journal of Anthropological Archaeology, 14: 125.

Carballo Arceo, L.X. (1986): Povoamento castrexo e romano da Terra de Trasdeza. Arqueoloxía-Investigación, 2. A Coruña.

- (1990): "Los castros de la cuenca media del río Ulla y sus relaciones con el medio físico". Trabajos de Prehistoria, 47: 161-199.

- (1993): "Espacio e povoamento castrexo de Galiza”. En Asociación Galega de Historiadores (ed.): Concepcións espaciais e estratexias territoriais na Historia de Galicia. Santiago de Compostela: 55-82.

Criado Boado, F. (dir.) (1992): Arqueología del Paisaje. El área Bocelo-Furelos entre los tiempos paleolíticos y medievales. Arqueoloxía/Investigación, 6. Santiago de Compostela.

- (1993): "Límites y posibilidades de laArqueología del Paisaje". SPAL, 2. 9-55.

DíAZ-DEL-Río, P. (1995): “Campesinado y gestión pluriactiva del ecosistema: un marco teórico para el análisis del III-II milenios a.C. en la Meseta peninsular". Trabajos de Prehistoria, 52 (2): 99-109.

Fernández-Posse, M. ${ }^{a}$ D. y SÁnchez-Palencia, F.J. (1988): La Corona y El Castro de Corporales II. Excavaciones Arqueológicas en España, 153. Madrid

Fernández-Posse, M. ${ }^{a}$ D.; Montero, I.; SÁnchez-Palencia, F.J. y Rovira, S. (1993): "Espacio y metalurgia en la Cultura Castreña: la ZonaArqueológica de Las Médulas". Trabajos de Prehistoria, 50: 197-220. 
Fernández-Posse, M. ${ }^{a}$ D.; SÁnchez-Palencia, F.J.; FernánDeZ Manzano, J. y Orejas, A. (1994): "Estructura social y territorio en la Cultura Castreña". Primer Congreso de Arqueología Peninsular (Porto, 1993).Actas IV. Trabalhos de Antropologia e Etnologia, 34 (3-4): 192-212.

GARCÍA FernándEZ-Albalat, B. (1990): Guerra y religión en la Gallaecia y Lusitania antiguas. Ed. El Castro. La Coruña.

- (1993): "El hecho religioso en la Galicia céltica". En Asociación Galega de Historiadores (ed.): O feito relixioso na Historia de Galicia. Santiago de Compostela: 27-58.

García Quintela, M.V. (1993): "Viriato y la ideología trifuncional indoeuropea". Polis, 5: 111-138.

Gilman GuillÉn, A. (1997): "Cómo valorar los sistemas de propiedad a partir de los datos arqueológicos". Trabajos de Prehistoria, 54 (2): 81-92.

GonZÁlez RodríGuez, M.C. (1986): Las unidades organizativas indígenas del área indoeuropea de Hispania. Anejos de Veleia, 2. Vitoria.

- (1993): "El papel de la mujer entre los cántabros". En J. Santos (dir.): Indígenas y romanos en el norte de la Península Ibérica. Ed. Universidad del País Vasco. San Sebastián: 51-65.

Kerblay, B. (1979): "Chayanov y la teoría del campesinado como un tipo específico de economía". En T. Shanin (coord.): Campesinos y sociedades campesinas. Fondo de Cultura Económica. México: 133-143.

Martins, M. y Jorge, S.O. (1993): "Sustrato cultural das etnias pré-romanas do Norte de Portugal". En M.Almagro-Gorbea y Ruiz Zapatero (eds.): Paleoetnología de la Península Ibérica. Complutum, 2-3: 347-372.

Pereira Menaut, G. (1982): "Los castella y las comunidades de Gallaecia". Zephyrus, 34-35: 249-268.

- (1993): "Aproximación crítica al estudio de etnogénesis: la experiencia de Gallaecia". En M.Almagro-Gorbea y G. Ruiz Zapatero (eds.): Paleoetnología de la Península Ibérica. Complutum, 2-3: 35-43.

Parcero Oubiña, C. (1995): "Elementos para el estudio de los paisajes castreños del Noroeste peninsular". Trabajos de Prehistoria, 52 (1): 127-144.

RAmIL REgo, P. (1994): “Antropización y evolución del medio vegetal durante la segunda mitad del Holoceno en las sierras septentrionales de Galicia". En F. Jordá (ed.): Geoarqueología. Actas de la $2^{a}$ Reunión internacional de Geoarqueología (1992): 119-134. Madrid.

Rodríguez, M.X. (1989): “Area de visión, topografía e territorialidade: o mundo dos castros". BoletínAuriense, XVIII-XIX: 22-30.

RÖSENER, W. (1990): Los campesinos en la Edad Media. Ed. Crítica. Barcelona.

SAlinAs de Frías, M. (1986): La organización tribal de los wettones. Ediciones Universidad de Salamanca. Salamanca.
Sánchez-Palencia, F.J. y Fernández-Posse, M.D. (1985): La Corona y El Castro de Corporales I. Truchas (León). Excavaciones Arqueológicas en España, 141. Madrid.

- (1993): "Poblamiento y minería prerromana y romana en el Noroeste peninsular". En J. Santos (dir.): Indígenas y romanos en el norte de la Península Ibérica. Ed. Universidad del País Vasco. San Sebastián: 201225

Sánchez-Palencia, F.J.; Fernández-Posse, M.D. y FernánDEZ Manzano, J. (1994): "La zona arqueológica de Las Médulas". 6 Congreso Hispano-Ruso de Historia. F.C. Banesto/CSIC. Madrid:123-141.

SÁnCheZ-PAlencia, F.J.; Fernández-Posse, M. ${ }^{a} D$.; FernánDeZ Manzano, J. y Orejas, A. (1996): La Zona arqueológica de Las Médulas. León. Guía arqueológica. Salamanca.

Santos Estévez, M.; Parcero Oubiña, C. y Criado Boado, F. (1997): "De la Arqueología Simbólica del Paisaje a la Arqueología de los Paisajes Sagrados". Trabajos de Prehistoria, 54 (2): 61-80.

Sastre Prats, I. (1998): Formas de dependencia social en el Noroeste peninsular. Transición del mundo prerromano al romano y época altoimperial. Instituto de Estudios Bercianos. Col. Bergidum. Ponferrada.

Shanin, T. (coord.) (1979): Campesinos y sociedades campesinas. Fondo de Cultura Económica. México.

- (1983): La clase incómoda. Sociología política del campesinado en una sociedad en desarrollo. Alianza Ed. Madrid.

Stirling, P. (1979): "Una aldea turca". En T. Shanin (coord.): Campesinos y sociedades campesinas. Fondo de Cultura Económica. México: 31-41.

THORnER, D. (1979): "La economía campesina como una categoría de la Historia Económica". En T. Shanin (coord.): Campesinos y sociedades campesinas. Fondo de Cultura Económica. México: 182-196.

VÁzquez Varela, J.M. (1983): "Los testimonios económicos". En G. Pereira (ed.): Estudos de Cultura Castrexa e de Historia Antiga de Galicia. Santiago de Compostela: 147-158.

- (1986): "Dieta real y dieta imaginaria". En J.C. Bermejo: Mitología y mitos de la Hispania prerromana 2. Ed. Akal. Madrid: 231-239.

- (1993): "El cultivo del mijo (Panicum miliaceum L.) en la Cultura Castreña del Noroeste de la Península Ibérica". Cuadernos de Estudios Gallegos, XLI: 65-73.

VicENT, J. (1991): "Fundamentos teórico-metodológicos para un programa de investigación arqueo-geográfica". En P. López (ed.): El cambio cultural del IV al II milenios a.C. en la comarca noroeste de Murcia. CSIC. Madrid: 29-119.

Wolf, E.R. (1982): Los campesinos. Ed. Labor. Barcelona.

T. P., 55, n. ${ }^{\circ} 2,1998$ 